\title{
Paleosuelos y tepetates del Glacis de Buenavista Morelos (México): testigos de eventos climáticos de la transición Pleistoceno-Holoceno
}

\author{
Jaime Díaz-Ortega ${ }^{1,2, *}$, Elizabeth Solleiro-Rebolledo ${ }^{1}$, Sergey Sedov ${ }^{1}$, Héctor Cabadas $^{2}$ \\ ${ }^{1}$ Instituto de Geología, Universidad Nacional Autónoma de México, Ciudad Universitaria 04360, México, D.F. \\ ${ }^{2}$ Posgrado en Ciencias de la Tierra, Universidad Nacional Autónoma de México, Ciudad Universitaria 04360, México, D.F. \\ *biotic78@yahoo.es
}

\section{Resumen}

La comprensión de los registros paleoclimáticos de finales del Pleistoceno, y en particular de la transición al Holoceno, es fundamental para el entendimiento del clima moderno. De este lapso, destaca el periodo Dryas Reciente (Younger Dryas), que representa una de las transiciones climáticas más dramáticas de la historia geológica reciente. Los registros paleoclimáticos en el interior del continente relacionados con este periodo se consideran de gran importancia para deducir la respuesta de los geosistemas a los cambios bruscos: deterioro del clima y su recuperación rápida. En este trabajo se presentan las evidencias paleopedológicas encontradas en el Glacis de Buenavista, Morelos, que ejemplifican las tendencias de cambio ambiental ocurrido en el periodo señalado. El clima actual en la zona muestra contrastes marcados, ya que hacia el norte (altitudes entre 2000-2200 m), es cálido-húmedo, en tanto que en el sur (altitudes entre 1800 y 1600) es cálido-semiseco, por lo que la cubierta edáfica actual conforma una climo-toposecuencia, que varía de Andosoles-Luvisoles a Vertisoles. Por su parte, los paleosuelos estudiados se refieren a un Albeluvisol (Buenavista), localizado en la parte norte y a un Gleysol (Ahuatenco), en la parte central de la geoforma. Sus edades, obtenidas por AMS, son de 12160 años A.P. y 12930 años A.P. (no calibradas), respectivamente. Las propiedades que muestran estos suelos (presencia de horizonte eluvial con procesos de estagnización superficial en el Albeluvisol, la fuerte gleyzación en el Gleysol, intemperismo moderado en ambos casos) indican un ambiente de formación húmedo-templado. Consecuentemente, no reflejan la gradación climática que se observa en la actualidad. El Gleysol se encuentra intercalado en una secuencia de tepetates (materiales volcánicos endurecidos), los cuales forman un manto entre los paleosuelos pleistocénicos y los suelos holocénicos. Su presencia se asocia con condiciones de inestabilidad climática y geomorfológica, debido a la intensa actividad volcánica y eventos torrenciales de lluvia, los cuales transportan materiales volcánicos y restos de suelos hacia la parte intermedia de la geoforma. Esta inestabilidad ambiental está relacionada con el Younger Dryas.

Palabras clave: Albeluvisol, Gleysol, tepetates, cambio paleoambiental, Younger Dryas.

\begin{abstract}
The knowledge of paleoclimatic records from the late Pleistocene, and in particular from the transition to the Holocene, is essential for understanding modern climate. From this period, the Younger Dryas stadial is noteworthy because it represents one of the most dramatic climate transitions in recent geological history. Paleoclimatic records of this period from the inland area of the continent are of great importance for understanding the response of geosystems to abrupt changes: deterioration of the climate and rapid recovery. In this paper, we present the paleopedological evidence found in the Glacis de Buenavista, Morelos, in order to show the trend of environmental change that occurred during that period. The current climate in the area shows marked contrasts, as the north (altitudes between 2000 and $2200 \mathrm{~m}$ ) is warm and humid, while the south (altitudes between 1800 and $1600 \mathrm{~m}$ ) is warmer and sub-humid. As a result, the current soil cover forms a climo-toposequence, which varies from Andosols-Luvisols to Vertisols. The studied paleosols correspond to an Albeluvisol (Buenavista), located on the north side, and a Gleysol (Ahuatenco) in the central part of the landform. Their ages, obtained by AMS, are 12160 years B.P. and 12930 years B.P. (uncalibrated), respectively. The properties shown by these
\end{abstract}


soils (presence of an eluvial horizon with surficial stagnic processes in the Albeluvisols, strong gleying in the Gleysol, moderate weathering in both cases) indicate a wet and warm environment of formation. Consequently, they do not reflect the climatic gradient observed today. The Gleysol is interbedded in a sequence of tepetates (hardened layers of volcanic materials), which form a stratum between the Pleistocene paleosols and Holocene soils. Its presence is associated with unstable climatic and geomorphic conditions due to intense volcanic activity and torrential rain events that transported volcanic materials and soil remnants to the middle part of the landform. This environmental instability is related to the Younger Dryas.

Keywords: Albeluvisols, Gleysols, tepetates, paleoenvironmental change, Younger Dryas.

\section{Introducción}

1.1. Problemática de la interpretación paleoambiental de la transición Pleistoceno-Holoceno: cómo contribuyen los paleosuelos

La transición del último glacial al Holoceno conforma el último evento climático de calentamiento global, cuya magnitud rebasa los escenarios más drásticos del calentamiento actual (Bennett et al., 2000). A nivel regional, se considera como un periodo dinámico y de cambios dramáticos en el clima, los ecosistemas y los paisajes de México. La comprensión de los registros paleoclimáticos de fines del Pleistoceno, y en particular de la transición al Holoceno, es fundamental para el entendimiento del clima moderno, así como de los mecanismos de cambio. Otro aspecto de interés es la definición de los paleoambientes en los cuales los primeros pobladores de México se asentaron, hace aproximadamente 10000 años A.P., según fechamientos instrumentales, disponibles de los restos humanos más antiguos (González et al., 2003). Con relación a esto último, también se presenta la interrogante sobre la extinción de la megafauna pleistocénica, la cual ocurre precisamente en esta época y cuyas causas propuestas siguen siendo controversiales (cambios climáticos versus impacto humano; Haynes, 1991; Lundelius y Graham, 1999; Ferrusquía-Villafranca et al., 2010).

La tendencia principal en la región central de México durante este periodo ( $c a .16000$ a 8500 años A.P.) marca un incremento de temperatura y de precipitación, que en términos generales coincide con la tendencia global (Heine, 1994). Sin embargo, varios autores coinciden en la detección de fuerte inestabilidad climática, caracterizada por ascensos y descensos de temperatura y precipitación en lapsos considerablemente breves, que probablemente se relacionaban con particularidades a nivel regional. Estas inferencias están basadas en diferentes registros paleoecológicos de alta resolución temporal: lacustres, glaciales y espeleológicos.

Por ejemplo, Vázquez-Selem y Heine (2004), en su síntesis de los datos paleoglaciológicos de varios volcanes del Centro de México, confirmaron 3 distintos avances de los glaciares durante el Pleistoceno final (después del Último Máximo Glacial) y el Holoceno temprano: Hueyatlaco 2,
Milpulco 1 y Milpulco 2, que indican intervalos de clima frío.

Los registros lacustres disponibles para el periodo considerado, que no son numerosos porque varias secuencias de este tipo muestran un hiato precisamente en este intervalo cronológico, como son los casos de Texcoco (Lozano-García y Ortega-Guerrero, 1998) y Tecocomulco (Caballero et al., 1999), también demuestran cambios ambientales bruscos y de intervalos cortos. En los diagramas polínicos de los sedimentos de los lagos Chignahuapan (Valle de Lerma; Lozano-García et al., 2005) y Chalco (Valle de México; Lozano-García y Ortega-Guerrero, 1994; Ortega-Guerrero et al., 2000) dichos cambios están representados por fuertes máximos de polen herbáceo. Estos máximos, que en muchos casos coinciden con variaciones en las propiedades magnéticas y fluctuaciones en el régimen paleolimnológico registrado por las diatomeas, se correlacionan con los avances glaciales. Sin embargo, las inferencias paleoclimáticas de los picos de polen noarbóreo es ambigua: en algunos casos se interpretan como indicadores de aridización (Ortega-Guerrero et al., 2000) y en otros como un desplazamiento de las zonas altitudinales y expansión del zacatonal, relacionados con una disminución de la temperatura (Lozano-García et al., 2005).

Por otro lado, los mecanismos y causas que están atrás de dichas señales paleoambientales no son claros. En varios estudios se ha buscado la relación directa entre las fluctuaciones locales y los eventos globales, en particular Vázquez-Selem y Heine (2004) declaran que "the overall pattern of glaciation is similar to those of mid latitude North America and Tropical South America thus supporting general sincroneity of major climatic events". Otros escenarios implican un control de los eventos globales, pero transformado (e inclusive invertido), de los procesos climáticos regionales. Heine (1994) detecta que los intervalos fríos en el centro de México ocurren antes y después, pero no sincrónicos con el Younger Dryas (1300011200 años A.P.), el episodio de enfriamiento global en el cual el clima de Norte América retornó a condiciones casi glaciares (Bennett et al., 2000). Heine (1994) vincula la disminución de la temperatura en la región con eventos de descarga masiva de las aguas producidas por la fusión del glaciar Laurentia hacia el Golfo de México, que corresponde a los intervalos de calentamiento en escala global. 
Cabe señalar que independientemente de los cambios climáticos globales, el periodo considerado está caracterizado por una alta actividad de procesos tectónicos y volcánicos regionales. En particular, varios estratovolcanes de la Faja Volcánica Transmexicana (FVTM) manifestaron erupciones violentas durante este periodo (Macías, 2005; Siebe et al., 2005), las cuales impactaron fuertemente el ambiente, de tal manera que también quedaron marcadas en los registros paleoecológicos. De hecho, se reconoce que el régimen de los sistemas lacustres del centro de México depende en gran medida del clima, y de la actividad volcánica y tectónica, por su influencia directa en las características de los sedimentos límnicos (Lozano-García y Ortega-Guerrero, 1998).

Es precisamente por esta alta variabilidad temporal y espacial, la cual no sólo está controlada por las fuerzas inherentes al clima sino también por factores múltiples como la actividad volcánica, los cambios altitudinales y del relieve y procesos tectónicos, entre otros, que se vuelve muy complicada la interpretación de los registros paleoclimáticos del Cuaternario de México.

Esto hace patente la necesidad de contar con una mayor variedad de registros que permitan establecer no sólo las tendencias generales de cambio ambiental, sino las particularidades regionales, lo cual está bien logrado por el registro paleopedológico (e.g., Solleiro-Rebolledo et al., 2006; Sedov et al., 2009). Una de las grandes ventajas de estos registros consiste en su alta resolución espacial (Targulian y Goryachkin, 2004), que permite reconstruir los factores paleoecológicos correspondientes específicamente al sitio donde ocurre la paleopedogénesis. Esta ventaja es clave para discriminar entre los procesos paleoambientales de diferente tipo y su escala geográfica (regional y local), así como para establecer la variabilidad espacial de los paleoambientes. Sin embargo, son muy controversiales las reconstrucciones basadas en los estudios paleopedológicos debido a su baja precisión cronológica. Efectivamente, los paleosuelos, siendo sistemas formados principalmente por procesos lentos, tienen una resolución temporal relativamente baja (típicamente de miles de años). Es importante señalar que las herramientas paleopedológicas no pretenden alcanzar el nivel de detalle de los archivos sedimentarios. Sin embargo, se debe destacar que son capaces de demostrar las tendencias paleoecológicas principales, de intervalos más largos, que se determinan de acuerdo a la capacidad de "filtro de la memoria edáfica" (Targulian y Goryachkin, 2004) que también tiene importancia para la reconstrucción de la historia ambiental.

Se considera que sitios en donde diversos procesos geomofológicos interactúan con la formación del suelo pueden brindar la información adicional para complementar la comprensión del sistema climático del centro de México, presentando registros más variados y con mayor resolución temporal.
1.2. Pedogénesis y sedimentación de la transición Pleistoceno-Holoceno grabadas en la cubierta edáfica actual. Tepetates como un fenómeno paleoambiental

Aparte de su contribución en las reconstrucciones paleoambientales, la identificación de los relictos edáficos de la época considerada tiene una gran importancia para la explicación de la cubierta edáfica actual. De hecho, el límite entre el Pleistoceno y el Holoceno marca el último periodo geológico en donde las condiciones ambientales de pedogénesis son diferentes, de manera contrastante y cualitativa, de las actuales, a nivel global. En el transcurso del Holoceno ocurrieron algunos cambios ecológicos, pero de menor escala, los cuales, en la mayoría de los casos, no cambiaron radicalmente el modo del desarrollo edáfico (salvo algunas excepciones donde la evolución edáfica holocénica es más contrastante, como por ejemplo las descritas por Alexandrovskiy et al. (1999) en el Cáucaso, que sin embargo son geográficamente limitadas). De hecho, la mayoría de los autores considera al suelo y a la pedogénesis "actual" o moderna como producto de procesos del Holoceno que siguen en la actualidad.

En cambio, los paleoambientes específicos de la época relacionada con la deglaciación y el calentamiento global que nos interesa, promovieron procesos de pedogénesis y sedimentación superficial de forma muy distinta que los actuales, los cuales se sobreponen a los anteriores. Entonces surge la pregunta: ¿Qué parte de los rasgos de varios suelos que constituyen el manto edáfico actual fueron generados (y siguen generándose) por los procesos "actuales" y cuáles representan la herencia de los procesos y ambientes de la época inmediatamente anterior (es decir, son relictos)?

Esta pregunta, aparte del interés teórico que reviste (procesos en suelos poligenéticos), tiene implicaciones prácticas importantes porque permite entender las propiedades edáficas claves para el funcionamiento ecológico y el uso agrícola de los suelos. Si ciertas características importantes (positivas o negativas) son producto de los procesos actuales, es probable que se puedan recuperar posteriormente en caso de su destrucción o alteración por la actividad humana; al contrario, si estas características se presentan como herencia de procesos y ambientes pasados, diferentes de los actuales, es posible que su pérdida sea irreversible.

Este problema está profundamente estudiado en las zonas templadas (paleo-periglaciales) de Europa, donde el contraste entre los ambientes actuales y los de la época de la deglaciación es notable. Se ha aceptado ampliamente que las propiedades de los suelos superficiales (red de fracturamiento, estructura laminar, deformación de los estratos, entre otros) fueron generados por procesos criogénicos, ocurridos durante del Pleistoceno final (Velichko et al., 1996; Van Vliet-Lanoë, 1998) y que han sido incorporadas a la edafogénesis actual. Inclusive, la 
suma de las propiedades tiene su efecto en la clasificación de los suelos de la zona templada. En particular, la diferenciación morfológica y granulométrica de los Luvisoles (tipo dominante en los bosques templados) ha sido interpretada por varios autores como un producto de la pedogénesis y sedimentación del periodo de deglaciación y se niega la importancia de los procesos de lixiviación e iluviación holocénica (Sokolov et al., 1983; Van Vliet-Lanoë et al., 1992).

Los cambios ecológicos dramáticos, documentados para la transición Pleistoceno-Holoceno en México, impulsan a la formulación de la misma pregunta a la cubierta edáfica regional, donde hasta ahora la discriminación entre los elementos actuales y heredados no se ha estudiado a profundidad. Con respecto a este problema, llamaron fuertemente nuestra atención los tepetates presentes en las secuencias volcániclásticas del Cuaternario tardío.

"Tepetates" es un término que se aplica a capas volcánicas endurecidas, sin importar el mecanismo de formación, las cuales ocurren en diversas regiones del centro de México asociadas comúnmente con suelos arcillosos. Tal es el caso de la parte NW de la Cuenca de México, en las cercanías del lago de Texcoco, en donde se han reportado en secuencias con Vertisoles (Oleschko et al., 2000; Prat et al., 2002); del área de Teotihuacan, con Luvisoles (McClung de Tapia et al., 2003) y de la cuenca alta de Tlaxcala, con Cambisoles arcillosos (Zebrowsky, 1992), Vertisoles y Luvisoles (Werner et al., 1978; Sedov et al., 2009). En el Glacis de Buenavista, estado de Morelos, se les ha encontrado intercalados con Luvisoles álbicos y Gleysoles, sobreyacidos por Luvisoles vérticos (SolleiroRebolledo et al., 2003). De acuerdo con las observaciones de campo e interpretaciones de imágenes de satélite, éstas no son las únicas áreas en que se localizan los paleosuelos arcillosos asociados con tepetates, sino que son elementos comunes de los piedemontes de las regiones montañosas de la FVTM (Gama-Castro et al., 2004).

Muchos estudios anteriores se enfocaron a determinar los agentes y mecanismos de endurecimiento de los tepetates así como a varios aspectos de su remediación y manejo agrícola, que inclusive llevó a la organización de tres Simposia Internacionales (Simposio internacional de suelos volcánicos endurecidos, 1992, y 2006, en México, y 1997, en Ecuador). Estos estudios asumieron, sin mayor discusión, que los tepetates son producto de los procesos (edáficos o edafosedimentarios) que ocurren actualmente, bajo condiciones ambientales modernas. Sin embargo, observando varias secuencias de estos estratos específicos que cuentan con una escala cronológica definida, nos dimos cuenta de que siempre se encuentran embebidos en las secuencias pleistocénicas y nunca en las de edad holocénica o reciente. Esto nos hace suponer que estos cuerpos se formaron en los ambientes del pasado y, a pesar de su importancia para el funcionamiento de los geosistemas actuales, no son productos de estos últimos. Es interesante que los análogos más cercanos de los tepetates
- los fragipanes en los Luvisoles de las zonas templadas de Europa - también se asocian con los procesos y paleoambientes pleistocénicos, muy distintos de los actuales (Van Vliet-Lanoë y Langohr, 1981).

En el estado de Michoacán, por ejemplo, se han observado suelos rojos y arcillosos (Luvisoles-Acrisoles), que sobreyacen a tepetates cuya génesis se asocia con la actividad volcánica del Pleistoceno Superior. Estos materiales se encuentran en una superficie geomorfológica similar al Glacis de Buenavista, por lo que presumiblemente su origen puede ser asociado. Esto nos hace suponer que sus propiedades reflejan una dinámica ambiental similar $\mathrm{y}$, entonces, las secuencias de paleosuelos-tepetates en diferentes partes de la FVTM constituyen registros paleoambientales comparables.

Tanto la problemática paleoecológica como edafogenética requiere del estudio de los objetos paleopedológicos (suelos, edafosedimentos, rasgos edáficos relictos) fechados, que correspondan precisamente a la transición PleistocenoHoloceno. La información sobre esos objetos a nivel regional todavía es escasa. En muchos casos los cuerpos edáficos desarrollados en este periodo no se reconocen, porque están "soldados" con los paleosuelos más antiguos o suelos modernos. La mayor probabilidad de encontrarlos aislados y no integrados en los objetos más jóvenes, se presenta en las secuencias edafosedimentarias (aluviales, lacustres, volcánicas) del Cuaternario tardío. En este caso, los paleosuelos buscados pueden estar perfectamente separados de los suelos más antiguos y más jóvenes por los estratos sedimentarios. Sin embargo, en varios geosistemas estudiados de este tipo los procesos sedimentarios a finales del Pleistoceno fueron tan intensos que inhibieron el desarrollo edáfico, como en el caso del perfil San Pablo en Teotihuacan (Solleiro-Rebolledo et al., en prensa), o permitieron sólo el desarrollo de suelos primitivos (como PT0 en Toluca, Solleiro-Rebolledo et al., 2004, y TX1a en Tlaxcala, Sedov et al., 2009) o sinsedimentarios (caso de Tepexpan, Sedov et al., 2010). Esos últimos paleosuelos demuestran únicamente rasgos de procesos pedogenéticos rápidos (como acumulación de humus y gleización), y por eso representan un registro paleoambiental relativamente pobre.

Con el enfoque en estas dos tareas: la extracción de un indicador paleoambiental y la interpretación poligenética del desarrollo de la cubierta edáfica, se ha llevado a cabo una investigación detallada en el Glacis de Buenavista, Morelos, donde afloran paleosuelos y tepetates formados a finales del Pleistoceno (Solleiro-Rebolledo et al., 2003). Éstos muestran las siguientes ventajas, que aumentan su "memoria edáfica":

- Son objetos variados, que incluyen paleosuelos bien drenados con perfiles profundos y bien desarrollados, paleosuelos hidromórficos y edafosedimentos.

- Forman una toposecuencia, que permite relacionar la paleopedogénesis con el factor geomorfológico. 


\section{Materiales y métodos}

\subsection{Condiciones del sitio}

El Glacis de Buenavista constituye un abanico aluvial de edad pleistocénica que se localiza principalmente en la porción noroccidental del estado de Morelos, entre los paralelos $18^{\circ} 20^{\prime}$ y $19^{\circ} 08^{\prime}$ de latitud norte y los meridianos $98^{\circ} 37^{\prime}$ y $99^{\circ} 30^{\prime}$ de longitud oeste (Figura 1 ), conformando un relieve de piedemonte originado por fases de erosión-sedimentación desde el Plioceno (Ortiz, 1977) con materiales volcánicos procedentes de las Sierras de Zempoala y Chichinautzin, cubriendo una extensión de 202.7 km² (Martínez-García y López-Blanco, 2005). Geológicamente se ubica dentro del graben de Cuernavaca, que lleva una orientación preferencial NE-SO delimitado por dos fallas, al oeste la falla Chalma y al este la falla Cañón de Lobos (Macías, 2006). Estos elementos tectónicos parecen controlar la evolución del glacis, contribuyendo a la subsidencia de toda la zona.

La pendiente de esta geoforma, aunque variable, tiene valores promedio que oscilan entre 3 y $7^{\circ}$. En la parte norte, en la base de la Sierra de Zempoala, las pendientes son mayores a $30^{\circ}$, en tanto que en la parte baja y sur son menores que $5^{\circ}$. Asimismo, el glacis está surcado por barrancas profundas, que llevan una orientación NE-SW.

El clima cambia en función de las diferencias altitudinales. De hecho, en la porción norte se tiene una precipitación que excede con mucho la evapotranspiración, de tal manera que se presenta saturación de humedad entre los meses de mayo a noviembre (Figura 2a). Por su parte, en el sur, ambos parámetros muestran valores similares, de tal manera que se tiene un mayor déficit de agua (Figura $2 b)$. Esto se traduce en cambios en el régimen climático, pues al pie de la Sierra de Zempoala es de tipo templadosubhúmedo, en el centro semicálido-subhúmedo y en el sur cálido-subhúmedo.

Estos tipos climáticos, junto con los gradientes altitudinales, determinan la distribución espacial de la vegetación. En las partes más altas predomina el bosque de coníferas. A medida que decrece la altitud y se incrementa la temperatura, dicho bosque va siendo sustituido por el bosque mixto, bosque de juníperos, selva baja y, finalmente, bosque de galería predominante en las barrancas.

\subsection{Objetos de estudio: paleosuelos y tepetates}

Para la selección de los objetos de estudio se hicieron recorridos en el área para conocer la distribución de suelos, tepetates y pedosedimentos, caracterizarlos y definir las condiciones de sitio. El recorrido se basó en la revisión de materiales previos (Solleiro-Rebolledo et al., 1999, 2003; Guerrero, 2007; Díaz-Ortega, 2008), así como en el uso de imágenes satelitales y fotografías aéreas escala 1:10000. De acuerdo con esta información, se seleccionaron tres secciones de paleosuelos con tepetates ubicados en diferentes posiciones geomorfológicas. Dos de ellas, Buenavista y Ahuatenco (Figura 2), fueron estudiadas con detalle por Escamilla-Sarabia et al. (2002) y SolleiroRebolledo et al. (2003).

La sección de Buenavista (18 $57^{\prime} 40^{\prime \prime} \mathrm{N}, 99^{\circ} 18^{\prime} 40^{\prime \prime} \mathrm{W}$, $2000 \mathrm{msnm}$ ) se caracteriza por presentar un suelo moderno, Andosol, sepultando a varios paleosuelos arcillosos, cuyos contenidos de arcilla varían entre 70 y $80 \%$, y con altos porcentajes de Fe extraído con ditionito-citrato-bicarbonato (Fed), que reflejan su fuerte grado de intemperismo. La unidad 5 corresponde con un Albeluvisol, el cual posee un perfil casi completo en el que se reconocen horizontes $\mathrm{E} /$ $\mathrm{Bt} / \mathrm{BC} / \mathrm{C}$ (Figura 3). El horizonte $\mathrm{E}$ es de color claro, con lengüetas que entran en el horizonte inferior. El material es limoso y posee abundantes concreciones duras de $\mathrm{Fe}$ $\mathrm{Mn}$, de $2 \mathrm{~mm}$ de diámetro. El horizonte Bt está muy bien estructurado y es arcilloso. Los valores de las relaciones Feo/ Fed son pequeñas, en todos los casos menores a 1, lo que evidencia la alta cristalinidad de los compuestos de hierro. Por su parte, los valores de Sio y Alo son bajos, indicando una contribución pequeña de los minerales alofánicos.

La edad mínima de este suelo es de 12160 años \pm 140 años A.P. (Solleiro-Rebolledo et al., 2003), dado que fue determinada por medio del carbono contenido en las concreciones de $\mathrm{Fe}-\mathrm{Mn}$, presentes en el horizonte E, que se interpretan como formadas en la fase final del desarrollo del suelo. De acuerdo a los datos procedentes de las regiones templadas (Montagne et al., 2007), la formación de estas concreciones ocurre después de que el horizonte $\mathrm{Bt}$ (arcilloso) se ha constituido, el cual representa un material de baja permeabilidad que impide o frena el paso del agua, propiciando el hidromorfismo superficial.

La sección Ahuatenco $\left(18^{\circ} 56^{\prime} 15^{\prime \prime} \mathrm{N}, 9^{\circ} 15^{\prime} 55^{\prime \prime} \mathrm{W}, 1850\right.$ msnm) se puede dividir en dos partes morfológicamente diferentes: la superior caracterizada por presentar un pedocomplejo de tres horizontes $\mathrm{B}$ arcillosos, de coloración rojiza, y la inferior, de color más claro, que contiene una secuencia de tepetates (capas I-VII, Figura 4a). Estos últimos son de textura más gruesa y más duros que los horizontes B superiores y presentan planos de ruptura vertical que forman bloques poligonales (Figura 4b), los cuales pueden ser observados en la superficie de las terrazas de erosión (Solleiro-Rebolledo et al., 2003). Además de las capas ya estudiadas, se identificó un suelo sepultado en la secuencia, debajo de la capa IV, que fue analizado con mayor detalle en este trabajo (Figura 4a).

La tercera sección, denominada Santa Úrsula (18 56 $\left.9.3^{\prime \prime} \mathrm{N}, 99^{\circ} 17^{\prime} 29.2^{\prime \prime} \mathrm{W}, 1804 \mathrm{msnm}\right)$, contiene una secuencia de tres capas de tepetates (Figura 5a), que afloran en la superficie, y en la que lo suelos arcillosos sobreyacientes se han erosionado, de tal manera que sólo quedan relictos del mismo, en islas aisladas. Parte de los suelos erosionados forman edafosedimentos rojizos que sepultan los Vertisoles modernos (Figura 5b). 
$99^{\circ} 20^{\prime} \quad \mathrm{A}$

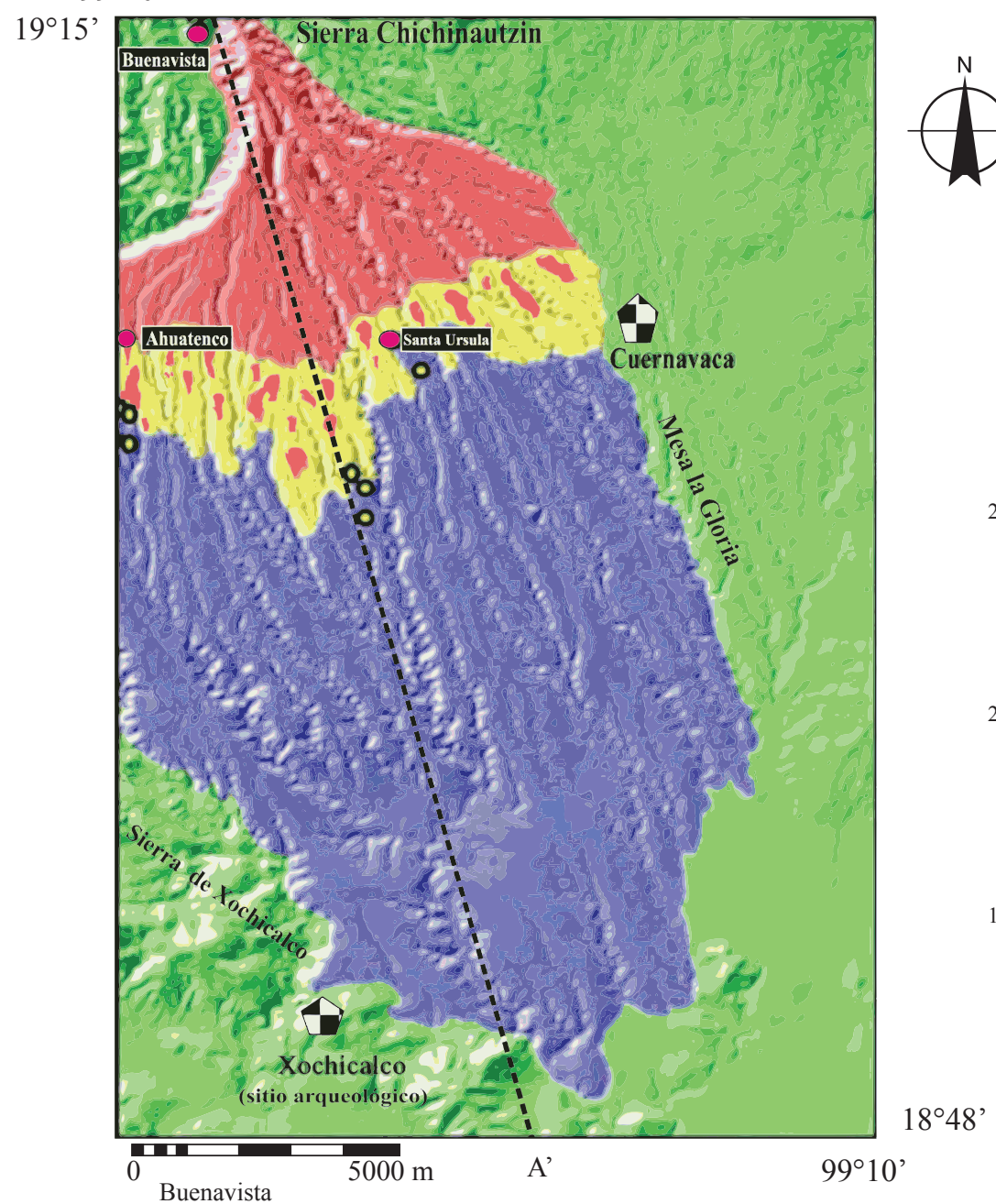

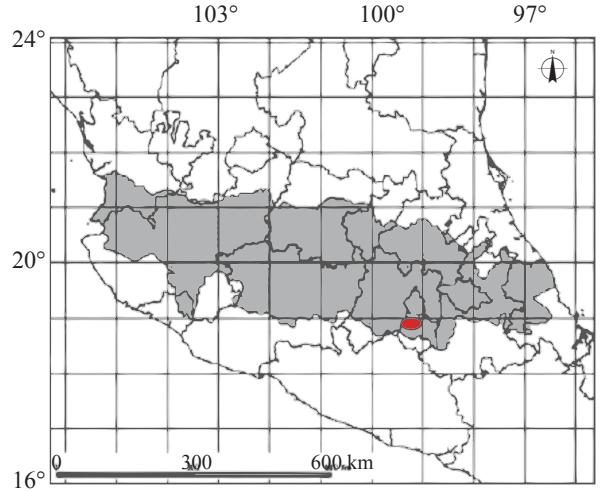

Faja Volcánica Transmexicana

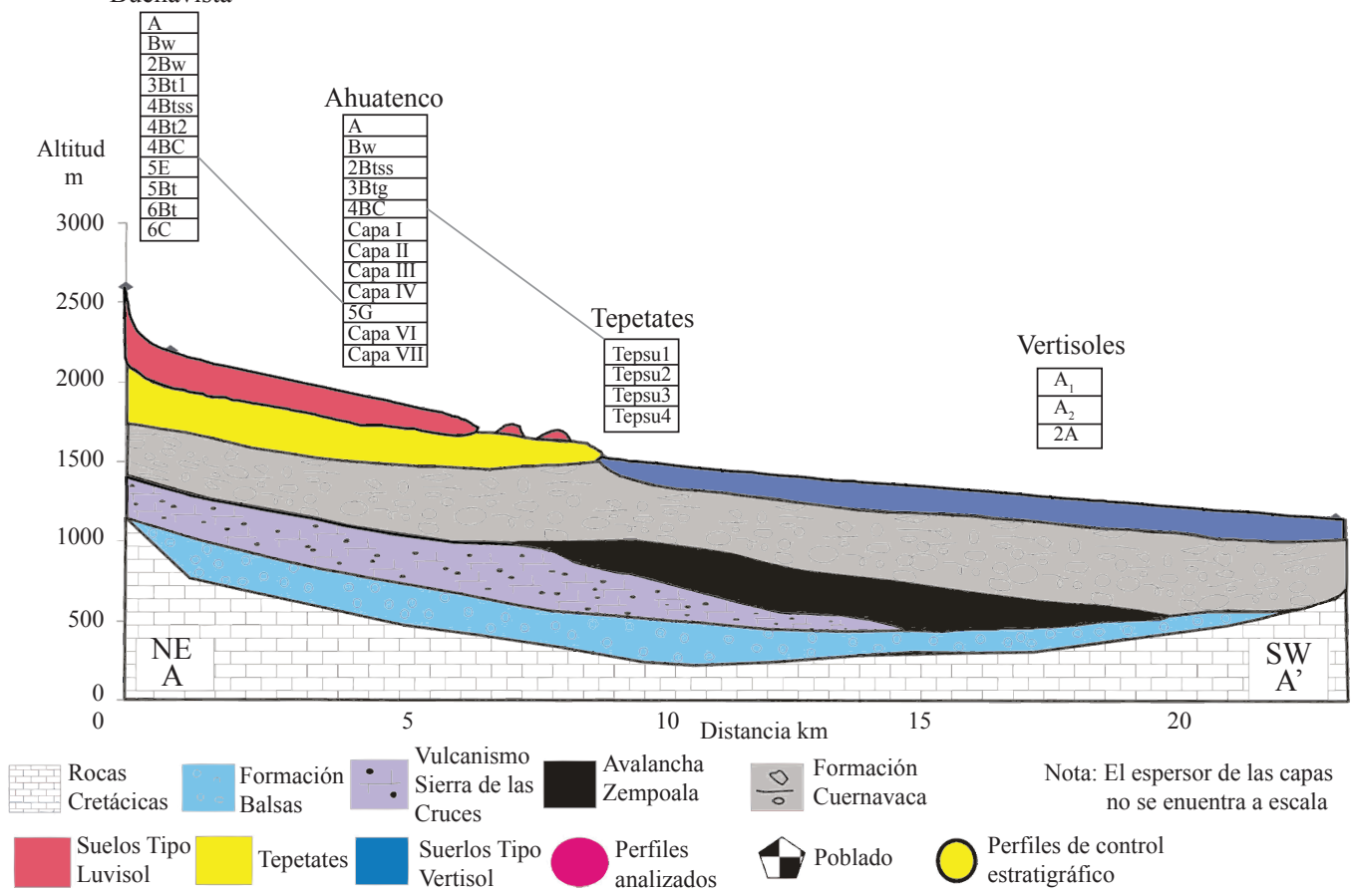

Figura 1. Localización y mapa altitudinal del Glacis de Buenavista. A-A’: Sección transversal. 
B

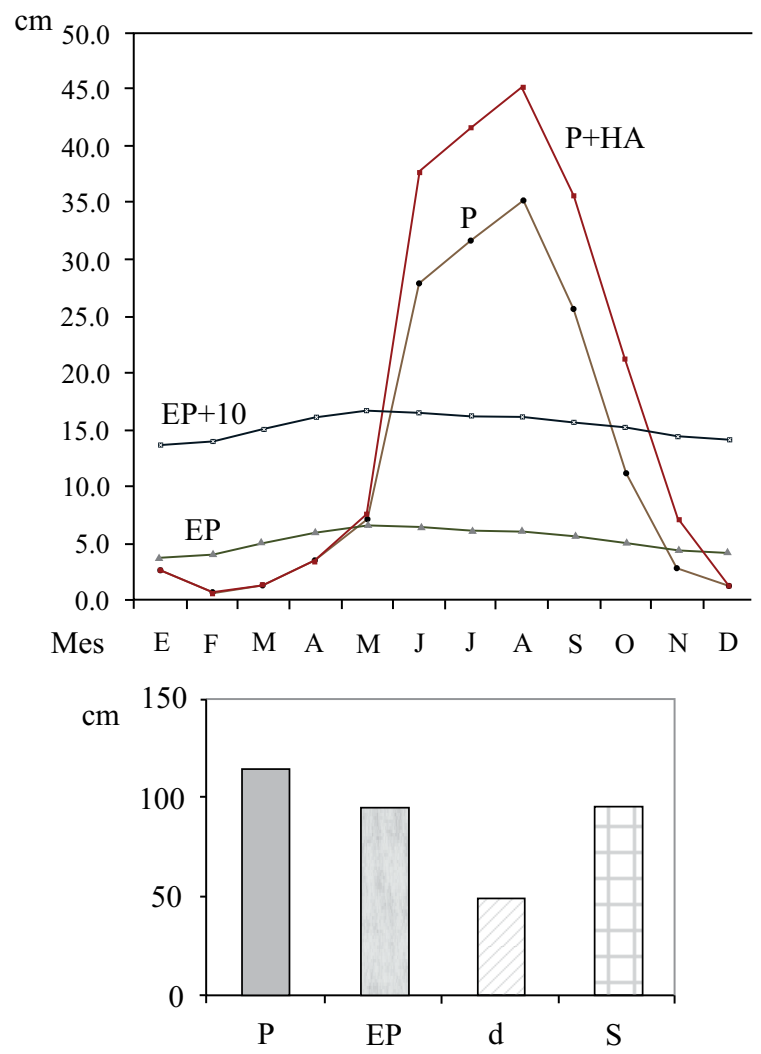

A
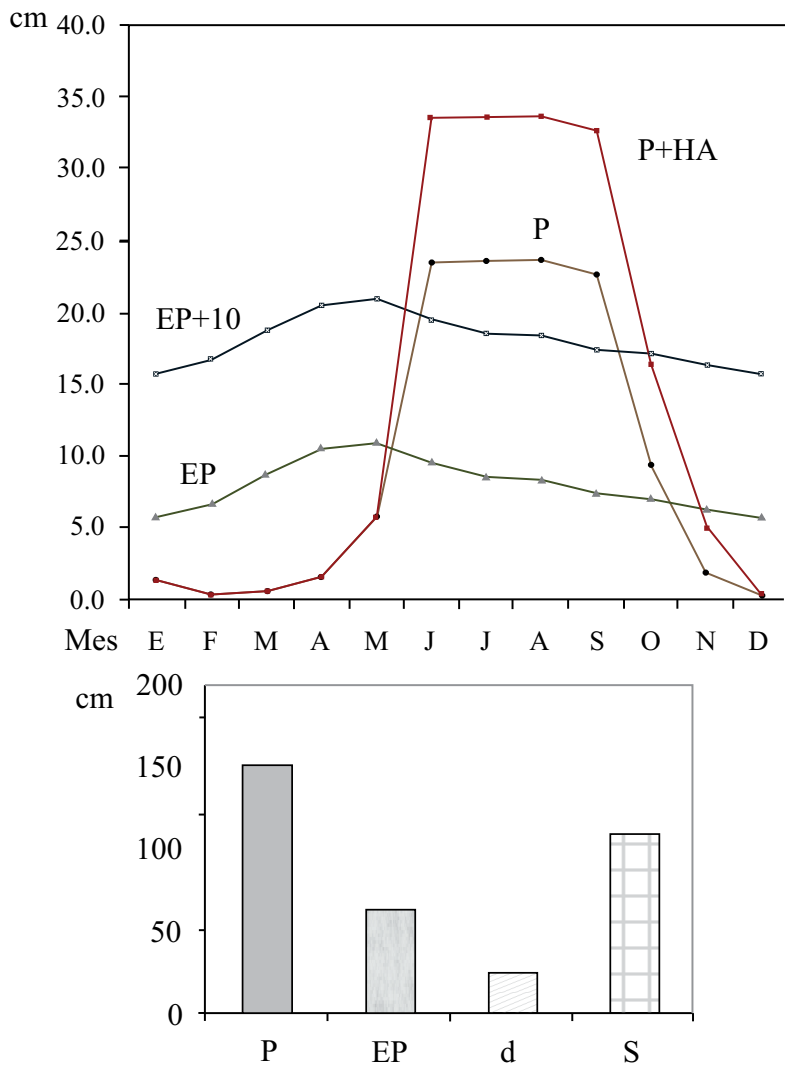

P: precipitación; EP: evapotranspiración; D: déficit de humedad; S: saturación de humedad; $\mathrm{P}+\mathrm{HA}$ : precipitación más agua almacenada.

Figura 2. Climogramas de la región de estudio: A. Estación Huitzilac; B. Estación Cuernavaca.

\subsection{Análisis de laboratorio}

Las capas de tepetates recolectadas en la sección Santa Úrsula, así como el Gleysol sepultado bajo las capas de tepetates de Ahuatenco, se analizaron en el laboratorio, siguiendo los criterios establecidos por USDA (1996). Se evaluó el color de las muestras tanto en húmedo como en seco, usando las tablas Munsell Color (1975). Se hizo una separación y cuantificación de las fracciones de arena, limo $\mathrm{y}$ arcilla, destruyendo previamente los agentes cementantes, como materia orgánica (con $\mathrm{H}_{2} \mathrm{O}_{2}$ al $10 \%$ ) y óxidos de hierro (con ditionito de sodio). La determinación de óxidos cristalinos de Fe se realizó mediante la extracción de ditionito-citrato-bicarbonato de sodio, en tanto que los óxidos de $\mathrm{Fe}, \mathrm{Si}, \mathrm{Al}$, amorfo se extrajeron con oxalato de amonio, siguiendo la metodología de Mehra y Jackson (1960).

La micromorfología se determinó por medio de observaciones de láminas delgadas bajo un microscopio óptico, definiendo rasgos de acuerdo a la terminología de Bullock et al. (1985). En el Albeluvisol Buenavista, se hicieron análisis micromorfológicos adicionales ya que este suelo es clave para el periodo considerado en esta investigación.

La mineralogía de la fracción arcilla se obtuvo por medio de difracción de rayos $\mathrm{X}$ en un difractómetro Philips Modelos 1130/96 (generador) y PW 1050/25 (goniómetro) semi-automatizado con registro digital de los datos, utilizando radiación $\mathrm{Cu} \mathrm{K} \alpha$ de foco fino, monocromada de grafito. Se obtuvieron patrones de difracción en muestras sin tratamiento, corriéndose de 4 a $70^{\circ}$ e identificándose los picos de arcilla. Con los patrones obtenidos se realizaron diversos tratamientos para identificar mejor las fases presentes: glicolación, calentamiento a $400^{\circ}$ y $550^{\circ}$, con mediciones en el intervalo angular de 4 a $20^{\circ}$. La identificación del tipo de arcillas fue realizada en base a la metodología de Starkey et al. (1984) por comparación con muestras estándar.

Para la determinación de los elementos mayores, menores y traza, se hicieron análisis de fluorescencia de rayos X en el Laboratorio de Fluorescencia de Rayos X del Instituto de Geología, UNAM. Con los contenidos de los elementos obtenidos, se calcularon índices de intemperismo (Tabla 1) que se asocian con el grado de desarrollo del suelo. Los valores bajos del índice $\mathrm{R}$, que determina la relación 
entre la cantidad de sílice y la alúmina, y del índice WIP (Índice de Intemperismo de Parker), que normaliza el porcentaje de las bases contenidas en el material, evidencian mayor grado de intemperismo y de desarrollo del suelo.

Con el objeto de verificar el tipo de horizontes genéticos presentes en el Albeluvisol de Buenavista, se realizaron mediciones de susceptibilidad magnética $(X)$ de baja

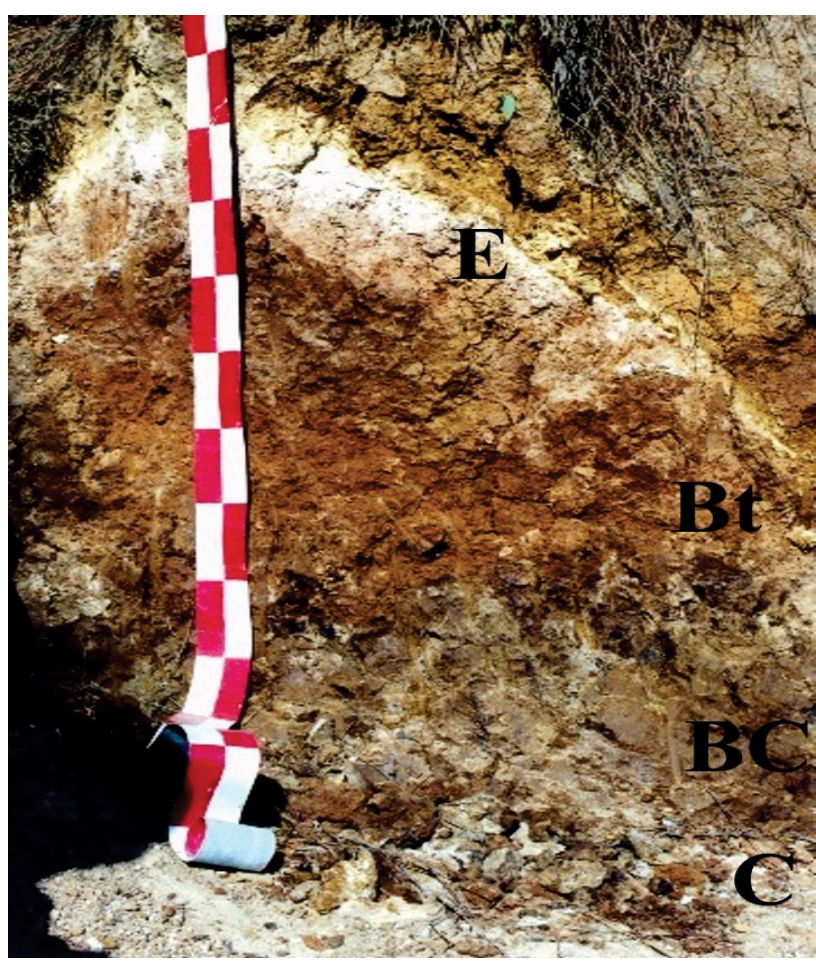

$20 \mathrm{~cm}$

Figura 3. Albeluvisol sepultado en la sección Buenavista. frecuencia $(0.47 \mathrm{kHz})$. Esta prueba ha demostrado ser útil para distinguir el horizonte $\mathrm{E}$ del horizonte $\mathrm{C}$, con diferenciación eluvial-iluvial, incluso en aquellos horizontes formados sobre sedimentos volcánicos (Rivas et al., 2006). Para la determinación, las muestras fueron homogenizadas y colocadas en cajas de acrílico de $8 \mathrm{~cm}^{3}$ en un sensor dual Barnington MS2B.

\subsection{Fechamiento}

Para establecer la edad de los tepetates, se tomó una muestra de materia orgánica que se encontraba embebida en la arcilla del Gleysol Ahuatenco. Dicha muestra se envío al laboratorio Beta Analytic, E.U.A., para su medición por AMS (Accelerator Mass Spectrometry).

\section{Resultados}

\subsection{Características de los tepetates}

Los tepetates del glacis se encuentran en un área específica, a altitudes entre 2000 y $1650 \mathrm{msnm}$ (Figura 1). La fuerte erosión del suelo superficial de la zona ha provocado que los tepetates se encuentren expuestos, abarcando una extensión de $2.19 \mathrm{~km}^{2}$ (Díaz-Ortega, 2008), dejando sólo relictos del pedocomplejo, el cual destaca por su coloración rojiza (Figura 4).

Los tepetates de la sección Ahuatenco están formados por 7 capas (I-VII), cuyas características generales se encuentran en la Tabla 2 (Solleiro-Rebolledo et al., 2003). Intercalado entre estos tepetates, se encuentra un horizonte de suelo $(5 \mathrm{G})$, de color gris, denotando propiedades gleícas, con concreciones de $\mathrm{Fe}-\mathrm{Mn}$, duras, de 2 a $5 \mathrm{~mm}$ de diámetro. Este suelo no había sido identificado en el trabajo de a

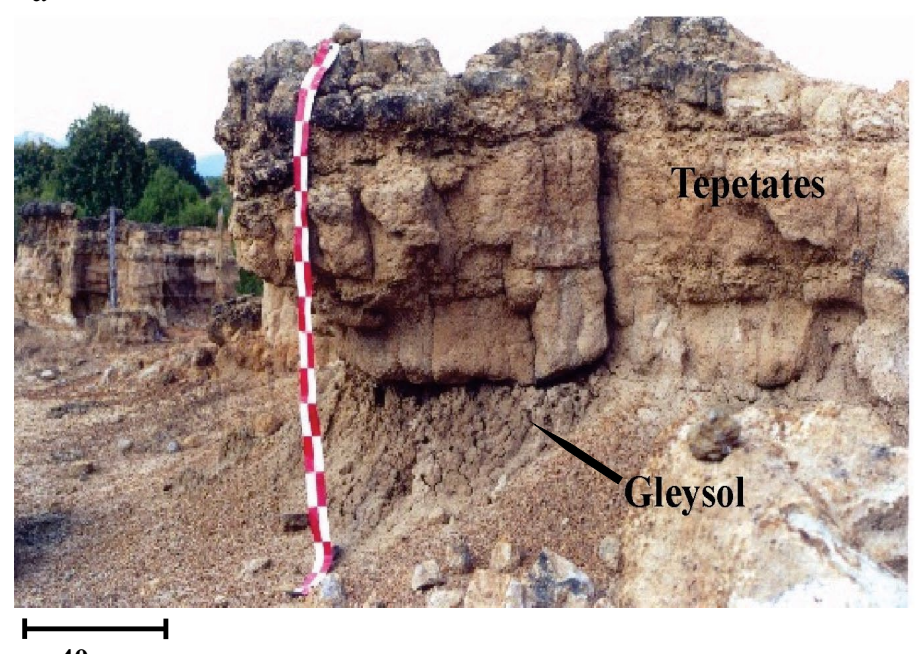

$\mathrm{b}$

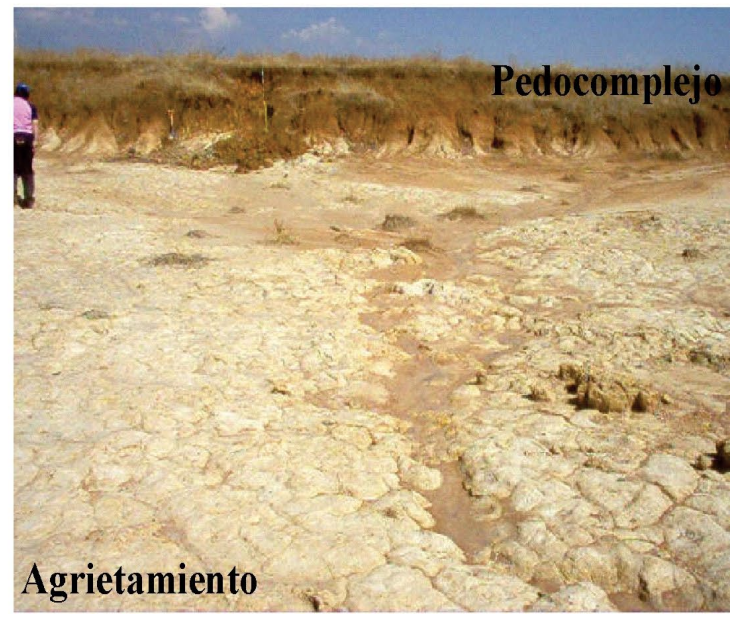

$40 \mathrm{~cm}$

Figura 4. (a) Tepetates de la sección Ahuatenco, mostrando el Gleysol sepultado; (b) agrietamiento poligonal en la superficie de los tepetates. 
Tabla 1. Fórmulas e interpretación de índices de intemperismo.

\begin{tabular}{ccccc}
\hline & Fórmula & $\begin{array}{c}\text { Valor de } \\
\text { Índice }\end{array}$ & $\begin{array}{c}\text { Valor de } \\
\text { materiales no } \\
\text { intemperizados } \\
\text { intemperizades }\end{array}$ & Referencias \\
\hline $\mathrm{R}$ & $\mathrm{SiO} 2 / \mathrm{Al} 2 \mathrm{O} 3$ & $>10$ & 0 & Ruxton $(1968)$ \\
WIP & $(100)[(\mathrm{Na} 2 \mathrm{O} / 0.35)+(\mathrm{MgO} / 0.9)+(\mathrm{K} 2 \mathrm{O} / 0.25)+(\mathrm{CaO} / 0.7)]$ & $>100$ & 0 & Parker $(1970)$ \\
\hline
\end{tabular}

R- Relación sílice/alúmina; WIP- Índice de intemperismo de Parker (Weathering Index of Parker).

Tabla 2. Propiedades selectas y mineralogía de la fracción arcilla de los paleosuelos y tepetates.

\begin{tabular}{|c|c|c|c|c|c|c|c|c|c|}
\hline Horizonte & Color en seco & $\begin{array}{l}\text { Arcilla } \\
(\%)\end{array}$ & Feo/Fed & Alo & Sio & Caolinita & Halloysita & Esmectita & Clorita \\
\hline \multicolumn{10}{|l|}{ Buenavista } \\
\hline $\mathrm{E}$ & 7.5 YR 7/4 & 40.4 & 0.18 & 0.16 & 0.42 & XX & $\mathrm{X}$ & & \\
\hline $\mathrm{Bt}$ & 7.5 YR 5/6 & 52 & 0.26 & 0.28 & 0.56 & $\mathrm{XX}$ & $\mathrm{X}$ & & \\
\hline $\mathrm{BC}$ & $7.5 \mathrm{YR} 4 / 4$ & 30.3 & 0.25 & 0.26 & 0.4 & XX & $X$ & & \\
\hline $\mathrm{C}$ & 7.5 YR 6/2 & 18 & 0.24 & $*$ & 0.28 & XX & $\mathrm{X}$ & & \\
\hline \multicolumn{10}{|l|}{ Ahuatenco } \\
\hline Capa I & 10 YR Y 7/4 & 69.1 & 0.17 & 0.2 & 0.11 & XX & & $\mathrm{X}$ & \\
\hline Capa II & 10 YR 8/4 & 27.9 & 0.09 & 0.07 & 0.06 & $\mathrm{XX}$ & & & \\
\hline Capa III & 7.5 YR 6/3 & 27.8 & 0.3 & 0.08 & 0.08 & XX & $\mathrm{X}$ & $\mathrm{X}$ & \\
\hline Capa IV & 7.5 YR 5/3 & 39.9 & 0.06 & 0.11 & 0.09 & $\mathrm{X}$ & $X$ & & $\mathrm{X}$ \\
\hline $5 \mathrm{G}$ & 10 YR 6/1 & 47.8 & 0.03 & 0.07 & 0.11 & XX & $\mathrm{X}$ & & \\
\hline Capa VI & $10 \mathrm{YR} 8 / 2$ & 45.9 & 0.01 & 0.08 & 0.05 & XX & $\mathrm{X}$ & & \\
\hline Capa VII & $10 \mathrm{YR} 3 / 4$ & 39.2 & 0.04 & 0.1 & 0.08 & XX & $\mathrm{X}$ & $X$ & \\
\hline \multicolumn{10}{|l|}{ Santa Úrsula } \\
\hline Tepsu 1 & 7.5 YR $6 / 6$ & 14 & 0.1 & 0.06 & 0.11 & & & & \\
\hline Tepsu 2 & 7.5 YR $6 / 4$ & 16.8 & 0.08 & 0.06 & 0.13 & $\mathrm{XX}$ & & & \\
\hline Tepsu 3 & 10YR 6/4 & 25.4 & 0.03 & 0.05 & 0.09 & XX & & & $X$ \\
\hline Tepsu4 & $10 \mathrm{YR} 7 / 2$ & 10.3 & 0.12 & 0.03 & 0.06 & $\mathrm{XX}$ & & & \\
\hline
\end{tabular}

Fed= hierro extraído con ditionito-citrato-bicarbonato; Feo, Sio, Alo= hierro, silicio y aluminio extraídos con oxalato ácido; XX abundante; X presente.

Solleiro-Rebolledo et al. (2003), pues se encuentra en una sección adicional, dentro de la localidad de Ahuatenco, y ocupa la posición de la capa V de tepetates. Este Gleysol, aunque es arcilloso, tiene un porcentaje más bajo de arcilla, en comparación con los paleosuelos del pedocomplejo sobreyaciente (40\%, Tabla 2). La relación Feo/Fed es muy baja, evidenciando la baja proporción de óxidos de hierro, tanto cristalinos como amorfos, lo cual es común en suelos hidromórficos (Acevedo-Sandoval et al., 2004). La materia orgánica se encuentra incorporada a la arcilla, pero formando acumulaciones que se observan como moteados de color gris oscuro. Se ha considerado que este suelo es un Gleysol, de acuerdo a los criterios de la WRB (IUSS working group WRB, 2006). Su edad fue obtenida por medio de un fechamiento AMS de la materia orgánica contenida en las acumulaciones de arcilla, arrojando una edad de
$12930 \pm 50$ años A.P. (Beta 196899), lo que nos brinda el marco cronológico de formación de estos materiales y permite establecer la correlación entre el Albeluvisol Buenavista y el Gleysol Ahuatenco. En la sección Santa Úrsula, en una posición opuesta a Ahuatenco pero a una altitud similar, sobre un interfluvio, los tepetates aparecen cubriendo la mayor parte del paisaje y el pedocomplejo rojo no se presenta; únicamente se observan pedosedimentos de coloración rojiza que demuestran la erosión y redepositación de suelos (Figura 5b). Se reconocieron 4 capas de tepetates, las cuales tienen límites abruptos y cambios en coloración muy marcados (Figura 5a).

El tepetate 1 (Tepsu1) es el más superficial $(0-30 \mathrm{~cm})$, de color en seco amarillo rojizo (7.5YR 6/6), con fuerte agrietamiento y estructura prismática. El tepetate 2 (Tepsu2; $30-95 \mathrm{~cm}$ ) tiene un color en seco pardo claro (7.5YR 6/4), 

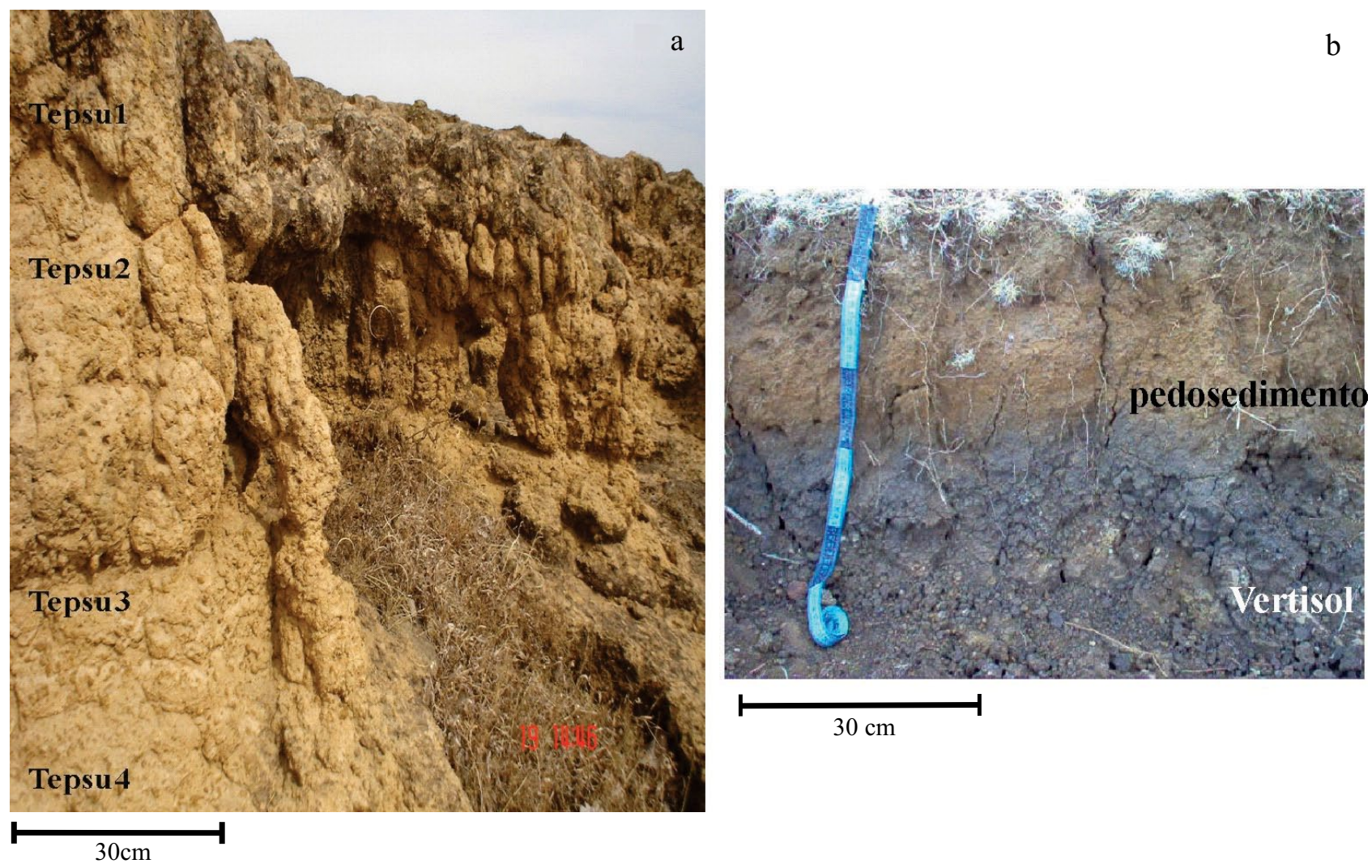

Figura 5. (a) Tepetates en la sección Santa Úrsula; (b) pedosedimentos que demuestran la intensa erosión de los suelos rojos del área.

presenta grietas orientadas verticalmente, con una estructura masiva. El tepetate 3 (Tepsu3; $95-220 \mathrm{~cm}$ ), de color pardo rojizo claro (10YR 6/4) también está agrietado, su estructura es masiva y muestra abundantes concreciones de Fe-Mn. En la matriz se pueden reconocer fragmentos de suelo. Tiene un límite abrupto con el tepetate 4 (Tepsu4), el cual tiene un color en seco gris claro (10YR 7/2), no presenta estructura y tiene una textura arenosa. De hecho, los porcentajes de arcilla de todos los tepetates son variables, oscilando entre 12 y $25 \%$ en Santa Úrsula, pero alcanzando valores de hasta $70 \%$ en Ahuatenco (Tabla 2). La relación de Feo/Fed es pequeña en todos los casos, al igual que los valores de Sio y Alo.

Los tepetates muestran rasgos micromorfológicos muy particulares. Varias de las capas poseen fragmentos de horizontes Bt que inclusive aún conservan los rellenos de arcilla iluviada (cutanes; Figura 6a). En ocasiones estos cutanes laminados se encuentran "sueltos", en forma de pápulas (Figura 6b), retrabajados en el sedimento, en el que se observan claramente minerales de origen volcánico no intemperizados. En particular las plagioclasas de composición intermedia son abundantes (Figura 6c). En los fragmentos de suelo se pueden encontrar restos de tejidos vegetales carbonizados (Figura 6d). Un rasgo común en estos materiales, que ya había sido reportado previamente por Solleiro-Rebolledo et al. (2003), es la presencia de fitolitos, algunos de ellos con coloraciones oscuras por materia orgánica, (Figura 6e) indicadores de que durante un tiempo estos materiales mantuvieron una vegetación incipiente, tal vez afectada por fuego. Los tepetates de esta zona, referidos como flujos hiperconcentrados, aún conservan rellenos arcillosos impuros con textura fluidal (Figura 6f). El conjunto de características observadas se resume en la Figura 7, en donde queda de manifiesto que los materiales son heterogéneos y poseen rasgos heredados de suelos erosionados que se integraron en su matriz.

\subsection{Características del Albeluvisol Buenavista}

Las características observadas en el Albeluvisol de Buenavista están encaminadas a mostrar los rasgos que permiten su distinción dentro de esta unidad taxonómica, es decir, la corroboración de la presencia del horizonte de eluviación (E). Precisamente la presencia del horizonte álbico pudiera ser confundido con una capa de ceniza de color claro. Las observaciones microscópicas del horizonte E permitieron detectar que posee una textura de arena finalimo, que en algunas partes se encuentra "blanqueado" y con nódulos de Fe (Figura 8a). Son comunes los siltanes (películas de limos) en poros, reflejando el lavado e 
$\mathrm{a}$
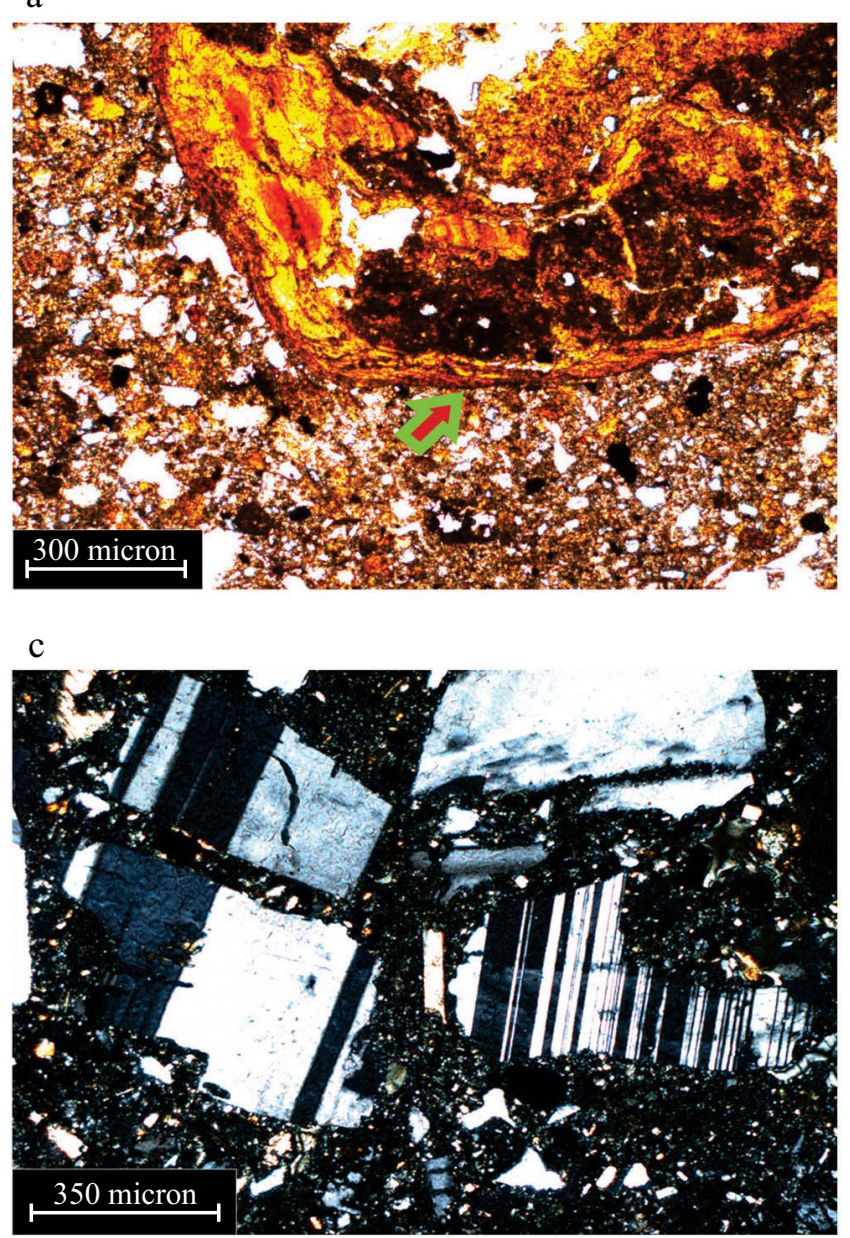

e

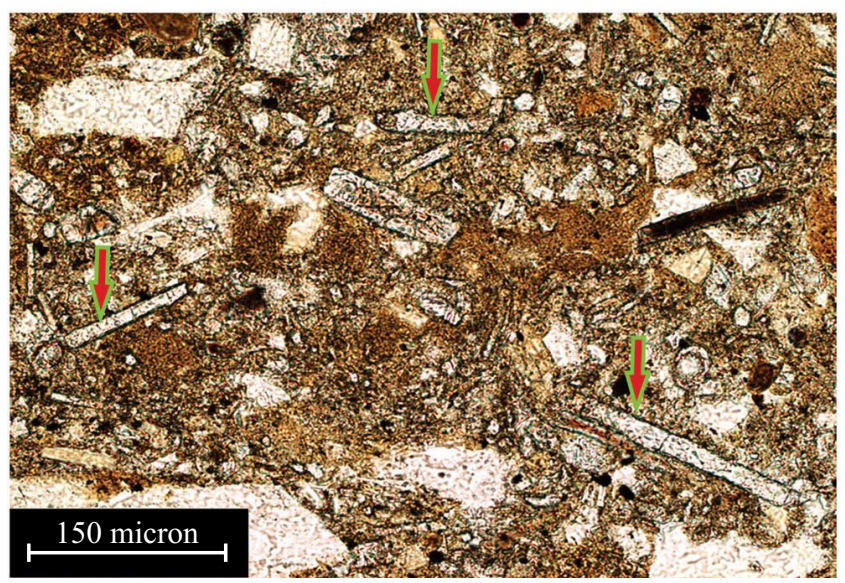

b

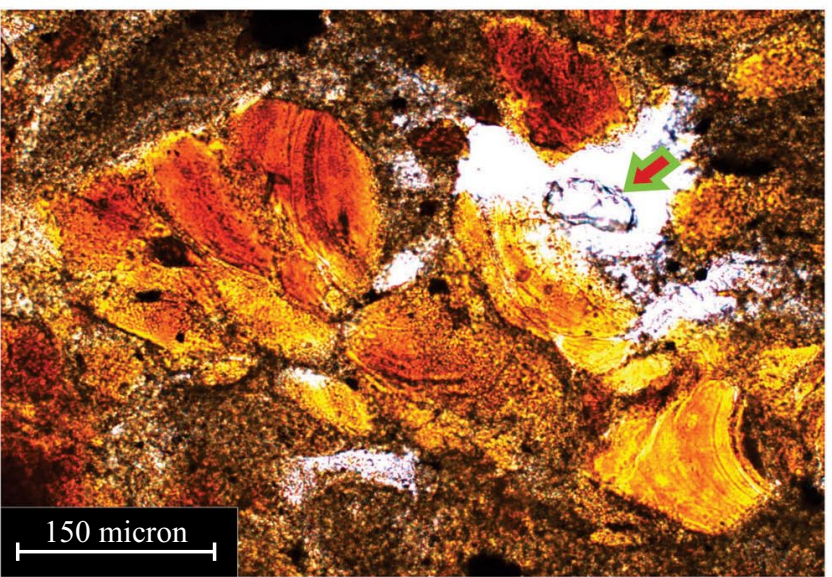

d

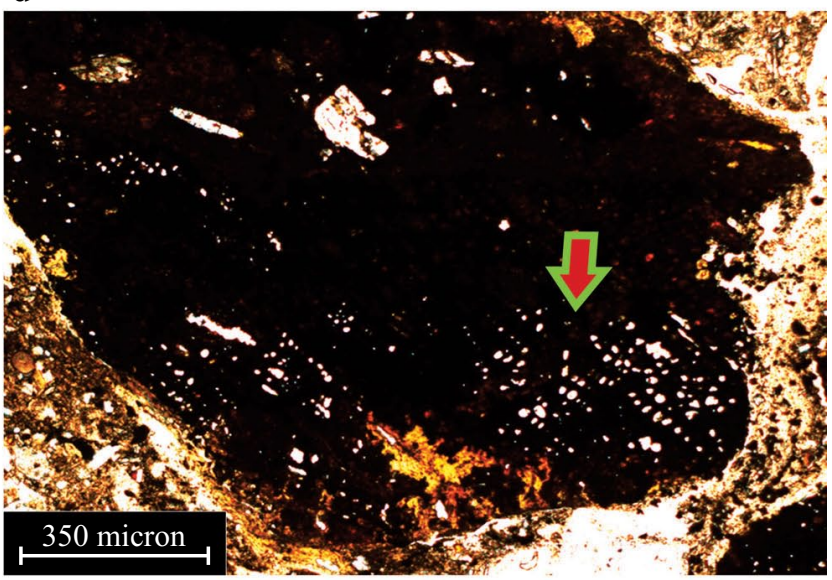

$\mathrm{f}$

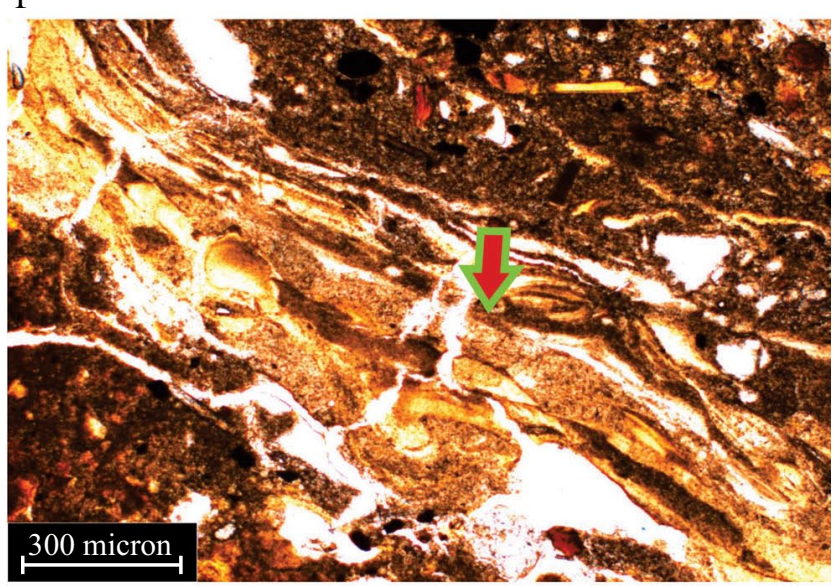

Figura 6. Micromorfología de los tepetates en las secciones Ahuatenco y Santa Úrsula. (a) Fragmento de horizonte Bt, con rellenos de arcilla iluviada en el tepetate de Ahuatenco. (b) "Pápulas" - fragmentos de cutanes de iluviación, con microlaminación. (c) Plagioclasas frescas en la matriz del tepetate. (d) Fragmento de suelo con tejido vegetal carbonizado. (e) Fitolitos incorporados en la matriz del tepetate, algunos de ellos tienen pigmentación obscura. (f) Rellenos arcillosos impuros, con textura fluidal.

indicando el carácter eluvial del horizonte (Figura 8b).

En el horizonte Bt se tiene una mayor alteración de los minerales primarios, con figuras de ataque, aunque en general el intemperismo no es tan intenso como en el caso anterior y aún se encuentran restos de los minerales primarios (Figura 8c). Por otro lado, en los horizontes Bt y BCt se encuentran frecuentes cutanes de iluviación in situ, sin deformación y fragmentación (Figura 8d). 


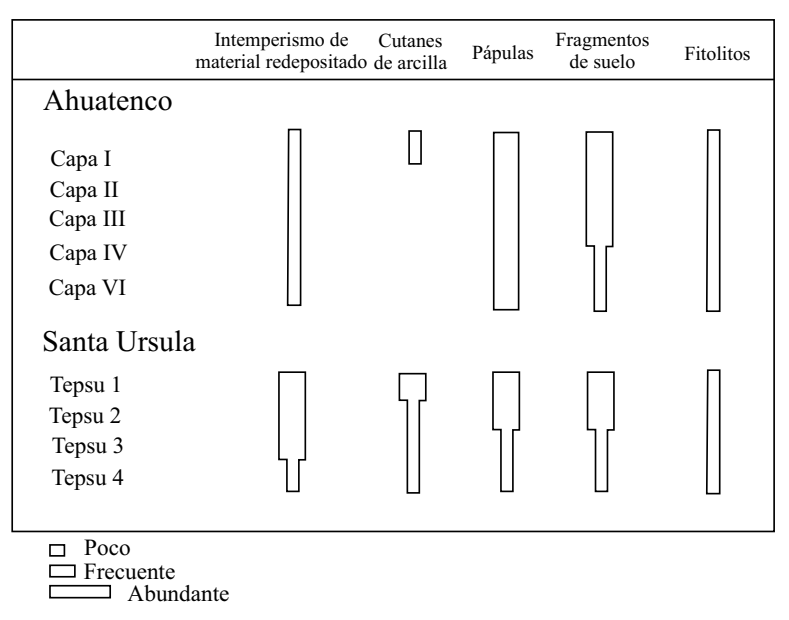

Figura 7. Resumen de los rasgos morfológicos encontrados en los tepetates.

En contraste con los rasgos descritos en el Albeluvisol, que marcan un carácter fuertemente reductomórfico, los suelos modernos y paleosuelos que sobreyacen a los tepetates muestran abundantes cutanes de iluviación, destruidos por el fracturamiento vértico (Figura 8e), así como cutanes de estrés (Figura 8f). La Figura 9 resume las propiedades morfológicas encontradas en los suelos del glacis.

El patrón de susceptibilidad magnética de baja frecuencia (X) del Albeluvisol, claramente demuestra diferencias entre sus horizontes genéticos. La tendencia del patrón de X es de aumento con la profundidad (Figura 10). Los valores más bajos se encuentran entre los 15 y $35 \mathrm{~cm}$, en lo que corresponde con el horizonte E. Estos valores contrastan con los que se observan en la parte superior del perfil ( 0 a $15 \mathrm{~cm})$, los cuales no están relacionados con el típico realce (enhancement) que se ha reportado para horizontes A en las secuencias loess-paleosuelos (Maher et al., 2003), sino que se asocian con ceniza volcánica que se encuentra en la parte superior del perfil y que lo sepulta parcialmente (SolleiroRebolledo et al., 2003). La susceptibilidad magnética en el horizonte $\mathrm{Bt}$ se incrementa ligeramente, e inclusive se tienen en algunos puntos valores similares a los encontrados en el E, lo que se explica por la presencia de las lengüetas de este último que entran en el Bt. El horizonte C muestra el valor más alto, lo cual es similar a lo encontrado para otros horizontes $\mathrm{C}$ de suelos volcánicos de México (OrtegaGuerrero et al., 2004; Rivas et al., 2006).

\section{3. Índices de intemperismo}

Como se observa en la Tabla 3 , todos los suelos poseen índices $\mathrm{R}$ (relación sílice/alúmina) $<5$, ligeramente mayores en los horizontes BC y C. El horizonte G del Gleysol sepultado debajo de los tepetates en Ahuatenco tiene un índice mayor, lo que denota una menor alteración; sin embargo, el índice de Parker (WIP) es menor, lo que indica un empobrecimiento en las bases. Este suelo se forma en condiciones de hidromorfismo, de tal manera que la saturación de agua y su posterior drenado propicia la lixiviación de elementos. Llama la atención que algunas capas de tepetates, sobretodo en Ahuatenco, tengan valores bajos en estos índices, inclusive menores que en los suelos de la misma zona, los cuales oscilan entre 2.5 y 3.6 (Escamilla-Sarabia et al., 2002), lo que se relaciona con una fuerte alteración.

En el caso del Albeluvisol Buenavista, tanto los valores de R como los de WIP tienden a disminuir con la profundidad. El horizonte E posee los valores más bajos en ambos índices, lo que remarca su mayor grado de alteración y lo diferencia claramente de los horizontes BC y C. Para los tepetates, los valores muestran una mayor dispersión (Tabla 3 ), pero se puede señalar que todos los materiales presentan valores bajos de $\mathrm{R}$, similares a los observados en los suelos. Las diferencias más notables se tienen en el WIP, ya que claramente demuestra que los tepetates 2 y 3 de Ahuatenco tienen valores altos, similares a los encontrados en Santa Úrsula, que marcan una mayor alteración y permiten su correlación.

\subsection{Mineralogía de la fracción arcilla}

Con respecto a la mineralogía de la fracción arcilla, es sorprendente la dominancia de caolinita en prácticamente todos los materiales estudiados, inclusive en los tepetates (que se consideran como los materiales menos intemperizados). Otras especies identificadas son las esmectitas aunque su proporción es baja. Asimismo, se encontraron clorita y la halloysita en algunas muestras (Tabla 2). Los tepetates superficiales de Ahuatenco (capas I y II) contienen caolinita y esmectita, en tanto que en los inferiores (VI y VII) hay caolinita y halloysita. En todos los materiales aparece adicionalmente cristobalita (Tabla 2). En los tepetates de Santa Úrsula se identificó caolinita como especie dominante. En el Albeluvisol se detectaron principalmente caolinita y halloysita. Estos dos minerales también aparecen en el Gleysol.

\section{Discusión}

4.1. Distribución y ambiente de formación de los suelos modernos, paleosuelos y tepetates

La cubierta edáfica actual en el Glacis de Buenavista coincide con una topo-climo-secuencia en donde la presencia de los suelos está controlada por el clima y el relieve. Los suelos tipo Andosol y Luvisol se encuentran en las posiciones de mayor altitud en donde las condiciones ambientales son más húmedas (Figura 2a), mientras que en las partes bajas se presentan Vertisoles (Díaz-Ortega, 2008), en áreas donde el clima es más seco y con una marcada estacionalidad (Figura $2 b$ ). 
a

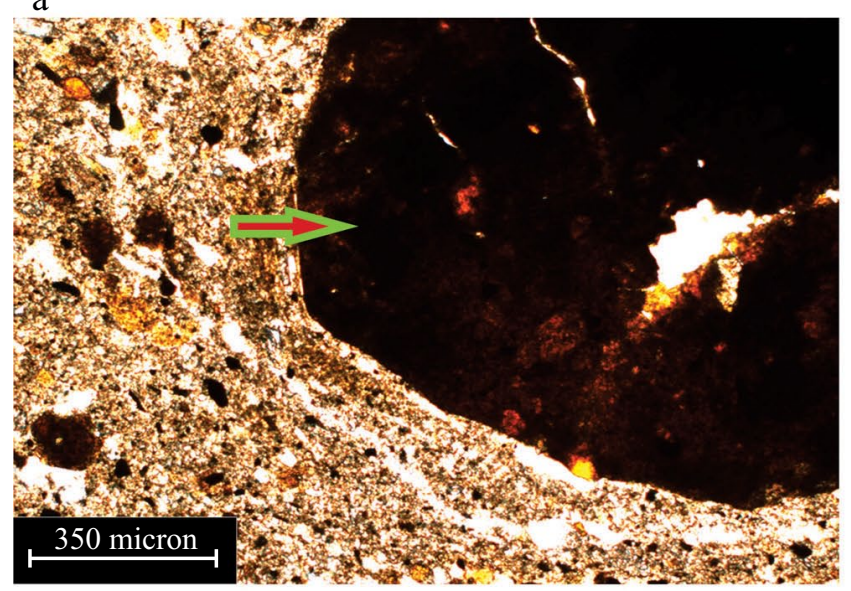

c

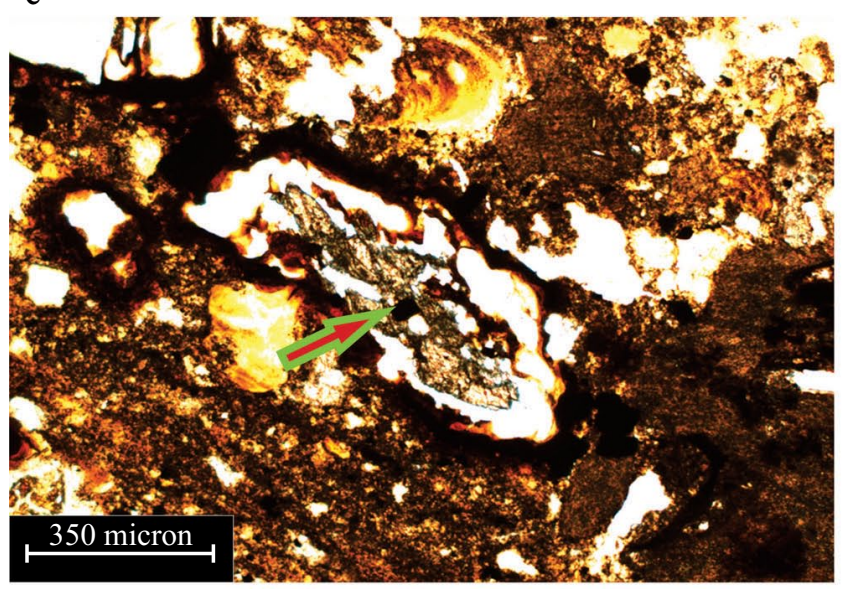

e

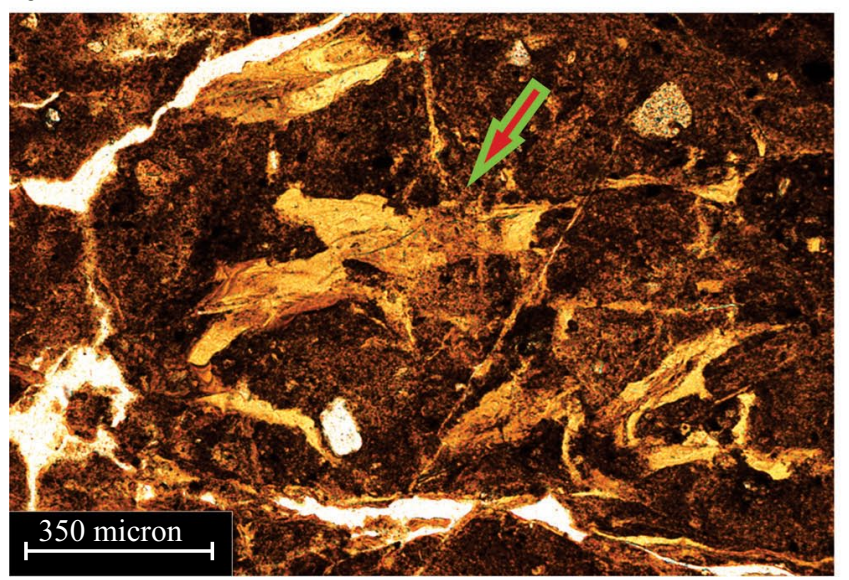

b

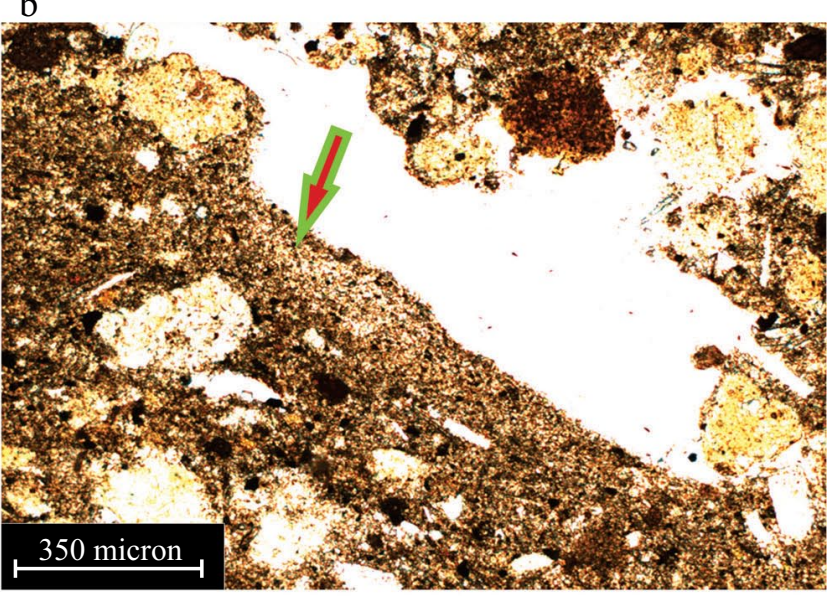

d

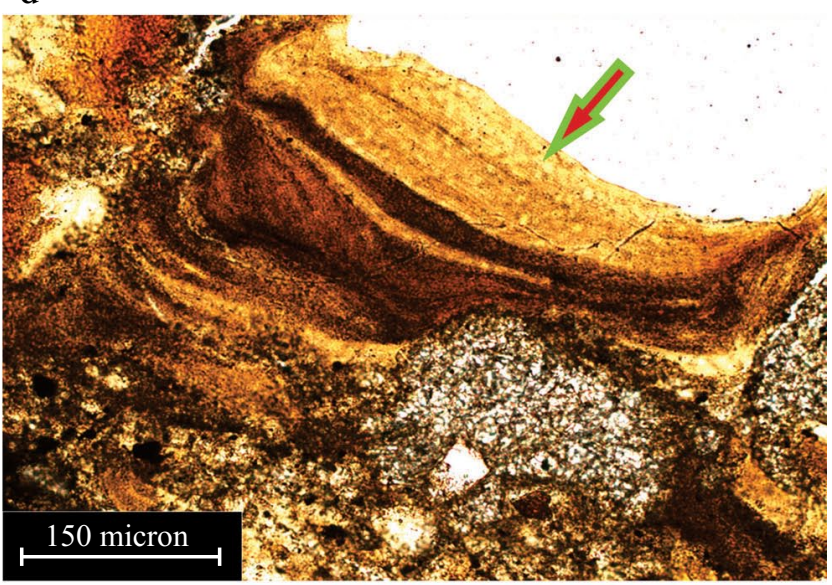

f

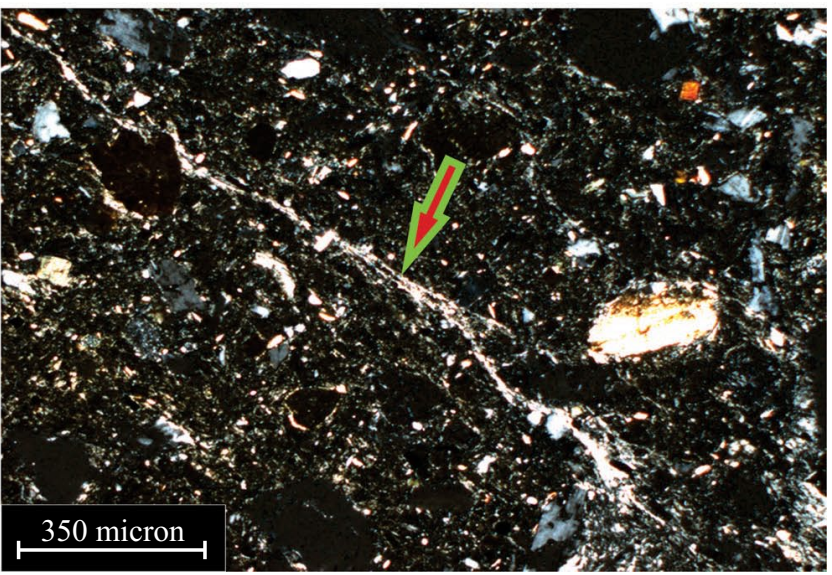

Figura 8. Micromorfología del Albeluvisol de Buenavista y del pedocomplejo Ahuatenco. (a) Nódulo de Fe, rodeado por la matriz areno-limosa, "blanqueada" en el horizonte E del Albeluvisol sepultado. (b) "Siltán" (película limosa en el poro) del horizonte E del Albeluvisol Buenavista. (c) Plagioclasa con figuras de ataque en el horizonte Bt del Albeluvisol Buenavista. (d) Cutanes de iluviación in situ en el horizonte Bt del Albeluvisol Buenavista. (e) Cutanes de iluviación, destruidos por fracturamiento vértico en el Luvisol vértico, del pedocomplejo Ahuatenco. (f) Cutanes de estrés en el horizonte A del pedocomplejo Ahuatenco.

Tomando en cuenta esta diferenciación edáfica en función del clima, los paleosuelos presentes en el glacis deberían responder de la misma manera a las variaciones locales, de acuerdo a su posición en el relieve, constituyendo una paleo-topo-climo-secuencia. El Albeluvisol Buenavista y el Gleysol Ahuatenco se encuentran a diferentes altitudes (Figura 1), el primero a $2000 \mathrm{msnm}$ y el segundo a 1850 msnm. Las propiedades que muestra el Albeluvisol, 


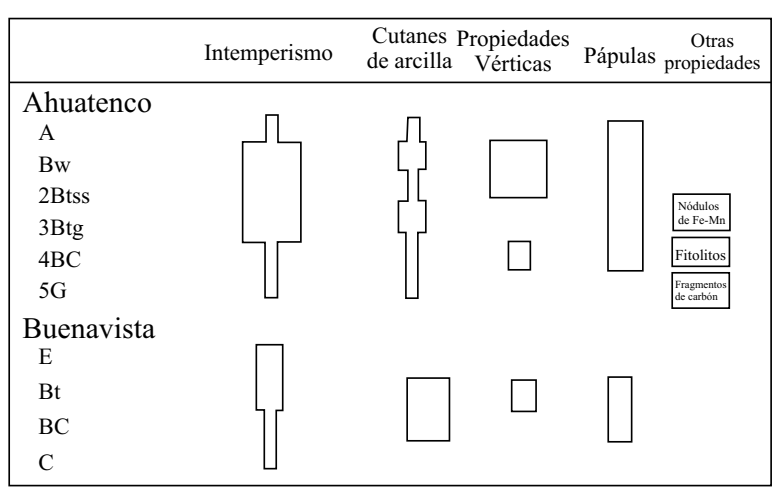

$\square$ Poco

$\square$ Frecuente

Figura 9. Resumen de los rasgos morfológicos encontrados en los paleosuelos y suelos modernos.

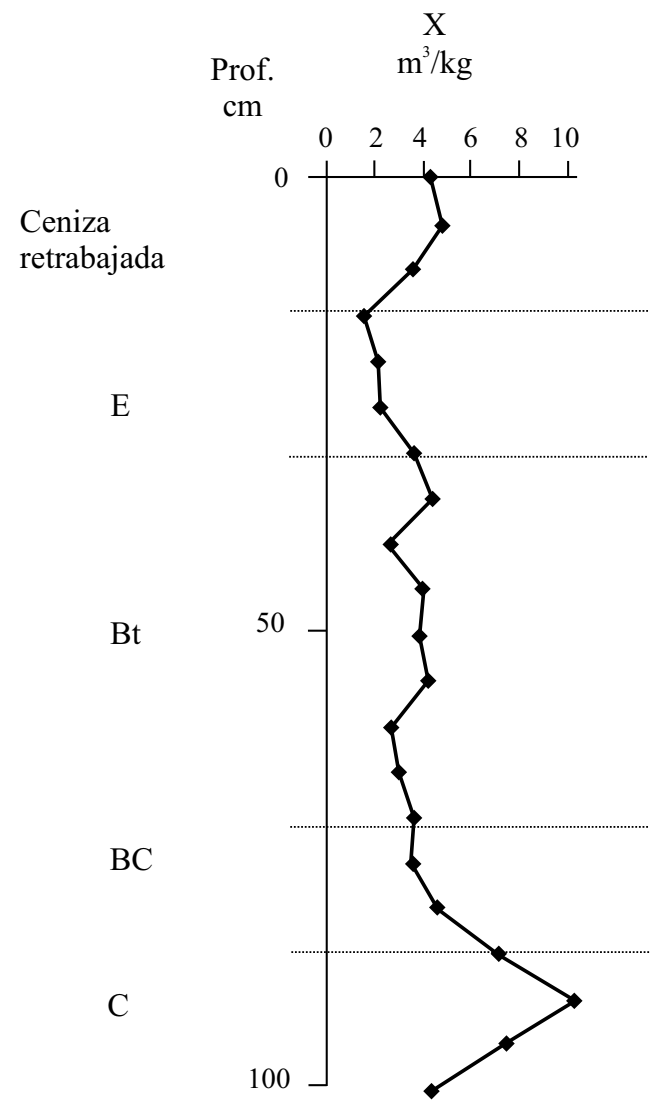

Figura 10. Patrón de susceptibilidad magnética de baja frecuencia $(\mathrm{X})$ en el Albeluvisol Buenavista.

son (1) un horizonte E con lengüetas y siltanes en las superficies de los peds, (2) un horizonte Bt con fuertes rasgos reductomórficos, que señalan condiciones estágnicas (saturación de agua por la entrada de lluvia al suelo), y (3) intemperismo moderado evidenciado por valores menores en los índices correspondientes (Tabla 3) y por
Tabla 3. Índices de intemperismo de los objetos estudiados.

\begin{tabular}{ccc}
\hline & \multicolumn{2}{c}{ Índices de intemperismo } \\
Horizonte & $\mathrm{R}$ & WIP \\
\hline Tepetates Ahuatenco & & \\
Capa I & 2.69 & 4.6 \\
Capa II & 3.75 & 20.4 \\
Capa III & 3.32 & 26.4 \\
Capa IV & 5.09 & 4.8 \\
5G & 6.62 & 3 \\
Capa VI & 4.63 & 3.2 \\
Capa VII & 4.5 & 4.2 \\
Albeluvisol Buenavista & & \\
5E & 2.69 & 4.3 \\
5Bt & 2.89 & 5.6 \\
5BC & 3.41 & 7.5 \\
5C & 3.26 & 7.5 \\
Tepetates Santa Úrsula & & \\
Tepsu2 & 5.6 & 17.6 \\
Tepsu3 & 6 & 21.2 \\
Tepsu4 & 6.8 & 21.6 \\
\hline
\end{tabular}

R- relación molar sílice/alúmina.

WIP- Índice de intemperismo de Parker (Weathering Index of Parker).

la alteración que muestran los minerales primarios (Figura 8). Por su parte, el Gleysol demuestra hidromorfismo relacionado con el ascenso del manto freático (coloraciones grisáceas, nódulos de Fe-Mn). Este tipo de asociaciones de suelos Albeluvisol-Gleysol son comunes en las zonas templadas del mundo (Urusevskaya, 1990; Birkeland, 1999). En consecuencia, por analogía, se interpreta que las condiciones presentes en el glacis para la formación de estas unidades son húmedas y templadas. Sin embargo, a pesar de que esta cubierta edáfica también está fuertemente controlada por el relieve y el clima, este último no presenta los contrastantes estacionales del clima actual (Figura 2), ya que ambas unidades fueron formadas bajo un ambiente de alta humedad.

Las edades de estos suelos, 12930 años A.P (15820 años cal) para el Albeluvisol Buenavista y 12160 años A.P. (14070 años cal) para el Gleysol Ahuatenco, permiten ubicarlos como productos del clima de finales del Pleistoceno. Dado que estas edades representan la edad mínima del suelo (es decir, su formación prácticamente finaliza en dicho periodo), la pedogénesis inicia anteriormente. Por otro lado, el grado de desarrollo que muestran estos suelos (presencia de un horizonte $\mathrm{Bt}$, con alto contenido de arcilla y bien estructurado) requiere de varios miles de años (alrededor de 10000 años; Birkeland, 1999; Targulian y Krasilnikov, 2007), por lo que su formación empieza durante el Último Máximo Glacial (UMG). Los indicadores paleoclimáticos que han caracterizado esta etapa final del Pleistoceno, 
particularmente el UMG, revelan resultados contradictorios. Por ejemplo Lozano-García y Ortega-Guerrero (1998) y Ortega-Guerrero et al. (2000), entre otros autores, interpretan el registro sedimentario del Último Máximo Glacial (UMG) en los lagos de Texcoco y Chalco como producto de condiciones frías y secas, en tanto que Bradbury $(1997,2000)$ señala que este periodo fue marcadamente más húmedo. Estas condiciones también han sido documentadas en los registros paleopedológicos del Nevado de Toluca (Sedov et al., 2001), el mismo Glacis de Buenavista (Solleiro-Rebolledo et al., 2003), Teotihuacan (SolleiroRebolledo et al., 2006), Tlaxcala (Sedov et al., 2009) y Tepexpan (Sedov et al., 2010). Por su parte, Metcalfe (2006) señala que el nivel del agua en el lago de Pátzcuaro era más alto que el actual, lo que refleja condiciones más húmedas. Esta humedad se asocia con una contribución de lluvias procedentes del Pacífico durante el invierno, debido a la localización más al sur de la Zona de Convergencia Intertropical. Estas observaciones coinciden con los datos de Watts y Bradbury (1982) procedentes del mismo lago y del lago de Chalco en la cuenca de México. Bradbury (1989) documenta en el lago de Texcoco la predominancia de un clima húmedo entre 15000 y 10000 años A.P, con cambios marcados hacia la aridez entre 9000 y 7000 años A.P., lo cual fue ratificado por Metcalfe (1995). Recientemente, Sedov et al. (2010), en un estudio multidisciplinario, analizaron una secuencia en Tepexpan y encontraron condiciones climáticas húmedas a fines del Pleistoceno, que se vuelven más secas en el Holoceno. El Albeluvisol Buenavista y el Gleysol revelan condiciones similares.

Los tepetates, acotados entre las altitudes de 1900 y $1600 \mathrm{msnm}$ en áreas en donde la pendiente oscila entre los 7 y $15^{\circ}$, están asociados con flujos hiperconcentrados, evidenciados por su morfología y por observaciones microscópicas (presencia de material volcánico fresco, restos de suelos erosionados y redepositados, arcilla con estructura fluidal). Se supone que la fuente de origen de los tepetates se encuentra en las partes altas, posiblemente en las sierras de Zempoala y Chichinautzin, y representan la parte distal del flujo.

Si bien los tepetates son materiales con débil desarrollo pedológico y su presencia está relacionada a eventos de sedimentación, su registro también responde a las condiciones del ambiente, ya que resultan de la interacción del vulcanismo con la reactivación de los procesos geomórficos. Durante los periodos de actividad volcánica se depositan materiales piroclásticos que se desplazan pendiente abajo con fuertes eventos de lluvias, en forma de flujos laháricos, y se depositan en las posiciones intermedias del glacis. Sin embargo, se considera que la lluvia es sólo torrencial, ya que inmediatamente después del depósito de los materiales se produce una sequía intensa que no permite su alteración completa. La evidencia de estos periodos de sequía se tiene en las grandes grietas de desecación que se observan en las superficies de los tepetates (Figuras 4 y 5), así como en la presencia de fitolitos en la matriz del suelo
(Figura 6) que muestran formas relacionadas a pastos.

Contradictoriamente, los tepetates, a pesar de su bajo grado de pedogénesis, muestran altos índices de intemperismo, así como presencia de minerales caoliníticos, los cuales se forman en ambientes de alteración intensa, bajo condiciones cálidas y húmedas. Los paleosuelos estudiados también contienen altas concentraciones de este tipo de arcillas. Sin embargo, se debe tomar en cuenta que tanto en los tepetates como en los paleosuelos, se observa no sólo material volcánico, sino fragmentos del suelo previamente formado, que fueron arrastrados e incorporados en su matriz. Esto demuestra que la cubierta edáfica previa al desarrollo del Albeluvisol, del Gleysol y de los tepetates correspondía a condiciones de mayor intemperismo, quizá bajo un clima húmedo pero más cálido, las cuales ya se han interpretado en las secuencias de paleosuelos en la base del perfil San Pablo de Teotihuacan (Solleiro-Rebolledo et al., en prensa), y en las unidades Parda y Roja de Tlaxcala, que son cuerpos edáficos contemporáneos a la Etapa Isotópica de Oxígeno 3 y más antiguos (Sedov et al., 2009).

\subsection{Albeluvisoles ¿suelos extintos en México?}

Como se ha señalado, la distribución de los Albeluvisoles en el mundo se limita a las zonas con clima boreal o templado bajo bosque de coníferas con inviernos fríos y veranos cortos y frescos. Cubren amplias superficies de Europa, Asia del norte y central (Driessen y Deckers, 2001). En la zona tropical son muy escasos y se encuentran restringidos a pequeñas inclusiones en las planicies aluviales bajas en el sur de Asia. Esto conduce a conceptualizar al Albeluvisol de Buenavista como un suelo extinto cuya ocurrencia no se repite en los paisajes modernos de México. Este Albeluvisol ha sido descrito previamente en otros puntos del glacis, y es posible que constituyera un manto continuo en las posiciones de mayor altitud de la geoforma (Solleiro-Rebolledo et al., 1999).

De acuerdo a los datos del Instituto Nacional de Geografía y Estadística (2003), de todas las unidades de suelos formalizadas por la WRB (IUSS working group WRB, 2006), los Albeluvisoles no están presentes en el territorio nacional. Por lo tanto, estos suelos reflejan el clima húmedo y frío de finales del Pleistoceno en la región tropical, condiciones que ya no se repiten. Hay otro caso de hallazgo de un Albeluvisol sepultado más antiguo en México, en la secuencia volcánica de Tlaxcala, que pertenece al Pleistoceno medio (Rivas et al., 2006; Sedov et al., 2009).

\section{Conclusiones}

De acuerdo a los datos anteriores, se concluye que a fines del Pleistoceno las condiciones en el glacis fueron húmedas y frías, desarrollando suelos de tipo Luvisol, con horizontes álbicos, posiblemente relacionadas al clima global de la época, cuando se torna más frío y con menores tasas de 
evapotranspiración, que incrementan la humedad ambiental. Formados en este periodo se tienen el Gleysol de Ahuatenco y el Albeluvisol Buenavista, los cuales representan dichos periodos de mayor humedad y menores temperaturas que las actuales, dada la menor intemperización que muestran los minerales primarios. Durante el periodo Younger Dryas, la inestabilidad geomorfológica que generaron tanto la actividad volcánica como los cambios climáticos globales produce flujos laháricos y el depósito de tepetates, los cuales marcan variaciones drásticas en las condiciones ambientales en la transición Pleistoceno-Holoceno.

A inicios del Holoceno el clima es aún húmedo, tal y como lo evidencia el pedocomplejo Ahuatenco (SolleiroRebolledo et al., 2003), el cual se vuelve paulatinamente más seco. La diferenciación climática de acuerdo a la altitud es notable, siendo más húmedo en el norte y dominado por una fuerte estacionalidad en la parte sur del glacis, tal y como lo evidencia la presencia de Andosoles y Vertisoles, respectivamente.

\section{Agradecimientos}

Este trabajo fue financiado por los proyectos PAPIIT IN112205 "Paleosuelos y tepetates de la Franja Volcánica Mexicana: interacción de sedimentación y pedogénesis durante el Cuaternario tardío”, PAPIIT IN110107 "Paleosuelos rojos en la base de las secuencias pedosedimentarias del Cuaternario de México: indicadores paleoclimáticos de la transición Plioceno-Pleistoceno" y PAPIIT IN117709 "Secuencias pedosedimentarias en registros aluviales del Cuaternario: proxies de estabilidad ambiental". Se agradece el apoyo de Jorge Gama, René Alcalá, Yazmín Rivera y Eligio Jiménez en los análisis de laboratorio, a Teresa Pi Puig por las difracciones de rayos X, a Patricia Girón del Laboratorio de Fluorescencia de Rayos X por los análisis de la composición química total, así como a Jorge Rivas, quien realizó las mediciones de susceptibilidad magnética del Albeluvisol Buenavista.

\section{Referencias}

Acevedo-Sandoval, O., Ortiz-Hernández, E., Cruz-Sánchez, M., CruzChávez, E., 2004, El papel de óxidos de hierro en suelos: Terra Latinoamericana, 22, 485-497.

Alexandrovsky, A.L., Sedov, S.N., Golyeva, A.A., 1999, Trends and rates of Holocene soil evolution in the North Caucasian Piedmont: Chinese Science Bulletin Special Supplement, 44, 193-199.

Bennett, K.D., Haberle, S.G., Lumley, S.H., 2000, The last glacialHolocene transition in southern Chile: Science, 290, 325-328.

Birkeland, P., 1999, Soils and Geomorphology: New York, Oxford University Press, 448 p.

Bradbury, J.P., 1989, Late Quaternary lacustrine paleoenvironments in the Cuenca de Mexico: Quaternary Science Reviews, 8, 75-100.

Bradbury, J.P., 1997, Sources of glacial moisture in Mesoamerica: Quaternary International, 43-44, 97-110.

Bradbury, J.P., 2000, Limnologic history of Lago de Pátzcuaro, Michoacán, Mexico, for the past 48000 years: impacts of climate and man:
Palaeogeography, Palaeoclimatology, Palaeoecology, 163, 69-95.

Bullock, P., Fedoroff, N., Jongeius, A., Stoops, G., Tursina, T., Babel, U., 1985, Handbook for soil thin section description: Wolverhamton, Reino Unido, Waine Research Publications, 152 p.

Caballero, M., Lozano, S., Ortega, B., Urrutia, J., Macías, J.L., 1999, Environmental characteristics of Lake Tecocomulco, northern basin of Mexico, for the last 50000 yrs: Journal of Paleolimnology, 22, 399-411.

Díaz-Ortega, J., 2008, Cambios ambientales y dinámica erosiva en el Glacís de Buenavista, Morelos, en el Cuaternario tardío: resultados paleopedológicos: México D.F., Universidad Nacional Autónoma de México, Tesis de maestría, $122 \mathrm{p}$.

Driessen, P., Deckers, J., 2001, Lecture notes on the major soils of the world (en línea): Roma, Food and Agriculture Organization of the United Nations, disponible en<http://www.fao.org/DOCREP/003/ Y1899E/Y1899E00.HTM>, consultado 20 de noviembre de 2007.

Escamilla-Sarabia, G., Solleiro-Rebolledo, E., Sedov, S., Gama-Castro, J., 2002, Tepetates del glacís de Buenavista, Morelos: interacción de procesos geomorfológicos y pedogenéticos: Investigaciones Geográficas, Boletín del Instituto de Geografía, 48, 76-89.

Ferrusquía-Villafranca, I., Arroyo-Cabrales, J., Martínez-Hernández, E., Gama-Castro, J., Ruiz-González J., Polaco, O.J., Johnson, E., 2010, Pleistocene mammals of Mexico: A critical review of regional chronofaunas, climate change response and biogeographic provinciality: Quaternary International, 217, 53-104.

Gama-Castro, J.E., Flores-Román, D., Solleiro-Rebolledo, E., JassoCastañeda, C., Rocha-Torrallardona, A.M., Villalpando-González, J.L., 2004, Neosols, relic paleosols and alterites in the Transmexican Volcanic Belt, Morelos state: Characterization and regional spatial distribution: Revista Mexicana de Ciencias Geológicas, 21, 160-174.

González, S., Jiménez-López, J.C., Hedges, R., Huddart, D., Ohman, J.C., Turner, A., Pompa y Padilla, J.A., 2003, Earliest humans in the Americas: new evidence from México: Journal of Human Evolution, 44, 379-387.

Guerrero, P., 2007, Caracterización y distribución de tepetates en el Glacis de Buenavista, México: interacción de procesos geomorfológicos y ambientales: México D.F., Universidad Nacional Autónoma de México, Tesis de licenciatura, $68 \mathrm{p}$.

Haynes, C.V.Jr., 1991, Geoarchaeological and paleohydrological evidence for a clovis-age drought in North America and its bearing on extinction: Quaternary Research, 35, 438-450.

Heine, K., 1994, The late-glacial moraine sequences in Mexico: is the evidence for the Younger Dryas event?: Palaeogeography, Palaeoclimatology, Palaeoecology, 112, 113-123.

Instituto Nacional de Estadística, Geografía e Informática (INEGI), 2003, Información Nacional sobre Perfiles de Suelo, Versión 1.2: México. D.F., 25 p.

IUSS working group WRB, 2006, World Reference Base for soils Resources: Roma, FAO World soil resources report No. 103, 132 p.

Lozano-Garcia, M.S., Ortega-Guerrero, B., 1994, Palynological and magnetic susceptibility records of Lake Chalco, central Mexico: Palaeogeography, Palaeoclimatology, Palaeoecology, 109, 177-191.

Lozano-García, M.S., Ortega-Guerrero, B., 1998, Late Quaternary environmental changes of the central part of the Basin of Mexico; correlation between Texcoco and Chalco Basins: Review of Palaeobotany and Palynology, 99, 77-93.

Lozano-García, M.S., Sosa-Nájera, S., Sugiura, Y., Caballero, M., 2005, 23,000 yr of vegetation history of the Upper Lerma, a tropical highaltitude basin in Central México: Quaternary Research, 64, 70-82.

Lundelius, E.L., Jr., Graham, R., 1999, The weather changed: Shifting climate dissolved ancient animal alliances: Discovering Archaeology, $1,48-50$.

Macías, J.L., 2005, Geología e historia eruptiva de algunos de los grandes volcanes activos de México: Boletín de la Sociedad Geológica Mexicana, 57, 379-424

Macías, V.R., 2006, Avalancha de escombros producida por el colapso de la porción S-SE del volcán Zempoala: Taxco el Viejo, Guerrero, México, Universidad Autónoma de Guerrero, Tesis de licenciatura, $95 \mathrm{p}$. 
Maher, B.A., Alekseev, A., Alekseeva, T., 2003, Magnetic mineralogy of soils across the Russian Steppe: climatic dependence of pedogenic magnetite formation: Palaeogeography, Palaeoclimatology, Palaeoecology, 201, 321-341.

Martínez-García, F., López-Blanco, J., 2005, Caracterización de las unidades ambientales biofísicas del Glacís de Buenavista, Morelos, mediante la aplicación del enfoque geomorfológico morfogenético: Investigaciones Geográficas, Boletín del Instituto de Geografía, $58,34-53$.

McClung de Tapia, E., Solleiro-Rebolledo, E., Gama-Castro, J., Villalpando, J.L., Sedov, S., 2003, Paleosols in the Teotihuacan valley, Mexico: evidence for paleoenvironment and human impact: Revista Mexicana de Ciencias Geológicas, 20, 270-282.

Mehra, O.P., Jackson M.L., 1960, Iron oxide removal from soil and clays by a dithionite-citrate system buffered with sodium bicarbonate buffer: Clays and Clay Minerals, 7, 317-327.

Metcalfe, S.E., 1995, Holocene environmental change in the Zacapu basin, Mexico: a diatom-based record: The Holocene, 5, 196-208.

Metcalfe, S.E., 2006, Late Quaternary environments of the Northern Deserts and central Transvolcanic Belt of Mexico: Annals of the Missouri Botanical Garden, 93, 258-273.

Montagne, D., Cousin, I., Le Forestier, L., Daroussi, J., Cornu, S., 2007, Quantification of soil volumes in the Eg \& Bt-horizon of an Albeluvisol using image analysis: Canadian Journal of Soil Science, 87, 51-59.

Munsell Color (Firm), 1975, Munsell soil color charts: Baltimore, Maryland, USA, Munsell Color, $34 \mathrm{p}$.

Oleschko, K., Figueroa, S.B., Miranda, M.E., Vuelvas, M.A., SolleiroRebolledo, E., 2000, Mass fractal dimensions and some selected physical properties of contrasting soils and sediments of Mexico: Soil and Tillage Research, 55, 43-61.

Ortega-Guerrero, B., Thompson, R., Urrutia-Fucugauchi, J., 2000, Magnetic properties of lake sediments from Lake Chalco, central Mexico, and their palaeoenvironmental implications: Journal of Quaternary Science, 15, 127-140.

Ortega-Guerrero, B., Sedov, S., Solleiro-Rebolledo, E., Soler, A., 2004, Magnetic mineralogy in Barranca Tlalpan exposure paleosols, Tlaxcala, Mexico: Revista Mexicana de Ciencias Geológicas, 21, 120-132.

Ortiz, P.M., 1977, Estudio geomorfológico del glacis de Buenavista, estado de Morelos: Investigaciones Geográficas, Boletín del Instituto de Geografía, 8, 25-40.

Parker, A., 1970, An index of weathering for silicate rocks: Geological Magazine, 107, 501-504

Prat, C., Ordaz, V., Rugada, J.A., 2002, Impacto de la roturación y del manejo agronómico de un tepetate sobre su estructura: TERRA, 21, 109-115.

Rivas, J., Ortega, B., Sedov, S., Solleiro, E., Sycheva, S., 2006, Rock magnetism and pedogenetic processes in Luvisol profiles: Examples from Central Russia and Central Mexico: Quaternary International, $156-157,212-223$.

Ruxton, B.P., 1968, Measures of the degree of chemical weathering of rocks: Journal of Geology 76, 518-527.

Sedov, S., Solleiro-Rebolledo, E., Gama-Castro, J.E., Vallejo-Gómez, E., González-Velázquez, A., 2001, Buried paleosols of Nevado de Toluca: an alterative record of Late Quaternary environmental change in Central Mexico: Journal of Quaternary Science, 16, 375-389.

Sedov, S., Solleiro-Rebolledo, E., Terhorst, B., Solé, J., Flores-Delgadillo, M.L., Werner, G., Poetsch, T., 2009, The Tlaxcala basin paleosol sequence: a multiscale proxy of middle to late Quaternary environmental change in central Mexico: Revista Mexicana de Ciencias Geológicas, 26, 448-465.

Sedov, S., Lozano-García, S., Solleiro-Rebolledo, E., McClung de Tapia, E., Ortega-Guerrero, B., Sosa-Nájera, S., 2010, Tepexpan revisited: A multiple proxy of local environmental changes in relation to human occupation from a paleolake shore section in Central Mexico: Geomorphology, 122, 309-322.

Siebe, C., Arana-Salinas, L., Abrams, M., 2005, Geology and radiocarbon ages of Tláloc, Tlacotenco, Cuauhtzin, Hijo del Cuauhtzin, Teuhtli, and Ocusacayo monogenetic volcanoes in the central part of the Sierra Chichinautzin, México: Journal of Volcanology and Geothermal Research, 141, 225-243.

Sokolov, I.A., Makeev O.A., Tursina T.V., 1983, Genesis of Soils with Texturally Differentiated Profiles: Pochvovedenie, 5, 129-142.

Solleiro-Rebolledo, E., Gama-Castro, E., Palacios-Mayorga, S., Shoba, S.A., Sedov, S., 1999, Late Pleistocene paleosols of Central Mexico: genesis and paleoenvironmental interpretation: Eurasian Soil Science, 32, 1077-1084.

Solleiro-Rebolledo, E., Sedov, S., Gama-Castro, J., Flores-Román, D. Escamilla-Sarabia, G., 2003, Paleosol-sedimentary sequences of the Glacís de Buenavista, central Mexico: interaction of Late Quaternary pedogenesis and volcanic sedimentation: Quaternary International, 106-107, 185-201.

Solleiro-Rebolledo, E., Macías, J.L., Gama-Castro, J., Sedov, S., 2004, Quaternary pedostratigraphy of the Nevado de Toluca volcano: Revista Mexicana de Ciencias Geológicas, 21, 101-109.

Solleiro-Rebolledo, E., Sedov, S., McClung de Tapia, E., Cabadas, H., Gama-Castro, J., Vallejo-Gómez, E., 2006, Spatial variability of environment change in the Teotihuacan valley during the Late Quaternary: paleopedological inferences: Quaternary International, 156-157, 13-31.

Solleiro-Rebolledo, E., Sycheva, S., Sedov, S., McClung de Tapia, E., Rivera-Uria, Y., Salcido-Berkovich, C., Kuznetsova, A., en prensa, Fluvial processes and paleopedogenesis in the Teotihuacan Valley, México: Responses to late Quaternary environmental changes: Quaternary International.

Starkey, H.C., Blackman, P.D., Hauff, P.L., 1984, The routine mineralogical analysis of clay bearing samples: U.S. Geological Survey Bulletin, 1563, 1-32.

Targulian, V.O., Goryachkin, S.V., 2004, Soil memory: Types of record, carriers, hierarchy and diversity: Revista Mexicana de Ciencias Geológicas, 21, 1-8.

Targulian, V.O., Krasilnikov, P.V., 2007, Soil system and pedogenic processes: Self-organization, time scales, and environmental significance: Catena, 71, 373-381.

Urusevskaya, I.S., 1990, Soil catenas in the nonchermozemic zone of Russian Federation: Pochvovedenie, 9, 12-27.

USDA (United States Department of Agriculture), 1996, Soil Survey Laboratory Methods Manual: Lincoln, Nebraska, E. U. A., Department of Agriculture-National Resources Conservation Services-National Soil Survey Center, Soil Survey Investigations Report No. 42 Version 3.0, $716 \mathrm{p}$

van Vliet, B., Langohr, R., 1981, Correlation between fragipans and permafrost with special reference to silty Weichsel deposits in Belgium and nothern France: Catena, 8, 137-154.

Van Vliet-Lanoë, B., 1998, Frost and soils: implications for paleosols, paleoclimates and stratigraphy: Catena, 34, 157-183.

Van Vliet-Lanoë, B., Fagnart, J-P., Langohr, R., Munaut, A., 1992, Importance de la succession des phases écologiques anciennes et actuelles dans la différentiation de sols lessivés de la couverture loessique d'Europe occidentale: argumentation stratigraphique et archéologique: Science du Sol, 30, 75-93.

Vázquez-Selem, L., Heine, K., 2004, Late Quaternary glaciation of Mexico, en Ehlers, J., Gibbard, P.L., (eds.), Quaternary Glaciations Extent and Chronology - Part III: South America, Asia, Africa, Australasia, Antarctica: Amsterdam, Países Bajos, Elsevier, 233-242.

Velichko, A.A., Morozova, T.D., Nechaev, V.P., Porozhnyakova, O.M., 1996, Paleocryogenesis: Soil Cover and Agriculture: Moscú, Rusia Nauka, $150 \mathrm{p}$.

Watts, W.A., Bradbury, J.P., 1982, Paleoecological studies at Lake Patzcuaro on the west-central Mexican Plateau and at Chalco in the Basin of Mexico: Quaternary Research, 17, 56-70.

Werner, G., Aeppli, H., Miehlich, G., Schönhals, E., 1978, Los suelos de la cuenca alta de Puebla-Tlaxcala y sus alrededores. Comentarios a un mapa de suelos: Puebla, México, Fundación Alemana para la Investigación Científica Proyecto Puebla-Tlaxcala, Comunicaciones $6,95 \mathrm{p}$. 
Zebrowski, C., 1992, Los suelos volcánicos endurecidos en América Latina: Terra, Número especial 10, 15-23.
Manuscrito recibido: Octubre 6, 2009

Manuscrito corregido recibido: Septiembre 23, 2010.

Manuscrito aceptado: Octubre 24, 2010. 